\title{
Le lion enfin couronné. Pensée politique et imaginaire royal au cours des premiers voyages espagnols des princes de la Maison de Bourgogne-Habsbourg
}

\author{
Jonathan DUMONT \\ Université de Liège \\ Transitions. UR sur le Moyen Âge \& la première Modernité
}

\begin{abstract}
« Le prince des Pays-Bas s'absorbe dans le roi d'Espagne et l'heure a sonné où les provinces bourguignonnes voient s'accomplir les conséquences du mariage de la duchesse Marie et de Maximilien. Leur «prince naturel», le descendant de la dynastie fondée par Philippe le Hardi leur échappe et se dénationalise, par une évolution toute contraire à celle qui, à la fin du XIV ${ }^{\mathrm{e}}$ siècle, avait détaché de la maison de France ses ancêtres maternels et les avait implantés dans les Pays-Bas $»{ }^{(1)}$.
\end{abstract}

Henri Pirenne voyait dans l'accession de Charles de Habsbourg aux trônes espagnols un moment de rupture politique et intellectuelle. Aujourd'hui, les historiens nuancent quelque peu la position du maître. Dans son Philippe le Beau, Jean-Marie Cauchies montre que la culture politique de Philippe et de son fils Charles de Habsbourg se traduisit dans une politique faite d'adaptation et de continuité, adaptation face au défi que représente l'héritage espagnol,

* Nous tenons à exprimer ici notre gratitude envers les professeurs Jean-Marie Cauchies (Université Saint-Louis-Bruxelles, Académie royale de Belgique), Jean Devaux (Université du Littoral-Côte d'Opale-Dunkerque) et Alain Marchandisse (FRS-FNRS, Université de Liège) pour les conseils bienveillants qu'ils nous ont apportés tout au long de l'élaboration de ce travail. Nous sommes également redevable envers le professeur Martha Howell (The Columbia University in the City of New York) qui nous accueillit, en 2014, en tant que Visiting Scholar. A cette occasion, nous eûmes l'opportunité de présenter une version " in progress » de ce travail à l'European History Workshop de Columbia. Les discussions qui s'en suivirent nous firent nous interroger en profondeur sur le sens à donner à cette recherche. Les échanges passionnants que nous eûmes, au fil de l'année écoulée, avec Renaud Adam (FRS-FNRS, Université de Liège), Michael Depreter (Université libre de Bruxelles, University of Oxford), Samuel Mareel (Universiteit Gent) et Christophe Masson (Université de Liège) ont considérablement élargi nos perspectives. Cet article ne serait pas ce qu'il est sans eux.

(1) Henri Pirenne, Histoire de Belgique, 4 éd., t. 3, Bruxelles, Maurice Lamertin, 1953, p. 87-88. 
continuité dans le souci de perpétuer le legs bourguignon ${ }^{(2)}$. Si rupture il y a, elle se révèle davantage au moment de l'élection impériale du 12 janvier 1519. L'héritage bourguignon cède alors le pas aux impératifs d'une politique impériale à vocation universelle et non plus uniquement dynastique ${ }^{(3)}$.

Les deux historiens se rejoignent toutefois sur un point essentiel : les premières expériences espagnoles des princes de la Maison de BourgogneHabsbourg amorcent des transformations profondes de la nature des fonctions qu'ils exercent ainsi qu'une réflexion intense, renouvelée, sur l'autorité, le pouvoir et la politique. D'archiduc d'Autriche et duc de Bourgogne, Philippe devient prince héritier de Castille, puis roi ; prince héritier, ensuite roi de Castille et d'Aragon, Charles ceint bientôt la couronne impériale. Cette succession rapide d'événements majeurs, en un peu moins de deux décennies, entraîne une nécessaire modification des idées, des symboles et des images qui, dans les Pays-Bas, à la cour de Bourgogne, expriment et donnent à voir le pouvoir du souverain. En d'autres termes, pour la dynastie de Bourgogne-Habsbourg, ce $\mathrm{XVI}^{\mathrm{e}}$ siècle naissant coïncide avec une reformulation de l'identité du prince lui-même.

L'accession de la Maison de Bourgogne à des fonctions royales représentait un vieux rêve poursuivi par les ducs, à tout le moins depuis Philippe le Bon ${ }^{(4)}$. Il leur fallut attendre le mariage entre Philippe le Beau et Jeanne, fille des Rois catholiques Ferdinand et Isabelle, célébré à Lierre le 20 octobre 1496,

(2) À propos de Philippe : «Son éducation, ses manières, sa cour étaient essentiellement bourguignonnes, c'est-à-dire organisées et vécues dans l'optique des seuls PaysBas, héritiers de ce nom de Bourgogne entretenant le souvenir du berceau dynastique perdu » (Jean-Marie CAUCHIES, Philippe le Beau. Le dernier duc de Bourgogne, Turnhout, Brepols, 2003, p. 245). Concernant Charles : "L'environnement culturel du jeune prince né à Gand et éduqué aux Pays-Bas allait demeurer longtemps celui d'un Bourguignon, au sens géographique (large) mais aussi familial du terme » (ibid., p. 248).

(3) Ibid., p. 250. Pierre Chaunu \& Michelle Escamilla, Charles Quint, Paris, Fayard, 2000, p. 110-111, lisent d'une façon fort similaire le début du règne personnel de Charles.

(4) Sur ce sujet, parmi une bibliographie fort abondante, voir Robert STEIN, De Hertog en zijn Staten. De eenwording van de Bourgondische Nederlanden, ca. 1380ca. 1480, Hilversum, Verloren, 2014, p. 18-21 (Stein décrit les États bourguignons comme une monarchie composite), 41-55 (il en repère les fondements notamment dans la titulature du prince, surtout dès Philippe le Bon) ; Arie Johan VANDERJAGT, Qui sa vertu anoblist. The Concepts of noblesse and chose publicque in Burgundian Political Thought (Including Fifteenth Century French Translations of Giovanni Aurispa, Buonaccorso da Montemagno, and Diego de Valera), Groningue, J. Mielot, 1981, p. 45-76 ; ainsi que D'Arcy Jonathan DACRE BOUlTON \& Johan R. VEenstra, eds, The Ideology of Burgundy. The Promotion of National Consciousness, 1364-1565, Leyde-Boston, Brill, 2006, et plus spécifiquement les contributions de Malte PrIETZEL, « Rhetoric, Politics and Propaganda. Guillaume Fillastre's Speeches », p. 117-129, et Johan R. VEENSTRA, « Le prince qui se veult faire de nouvel roy. Literature and Ideology of Burgundian Self-Determination », p. 195221. Quant au contexte politique dans lequel naît l'idée d'un " royaume de Bourgogne », on consultera Richard Vaughan, Philip the Good. The Apogee of Burgundy, nle éd., Woodbridge, Boydell, 2002, p. 285-296 ; ID., Charles the Bold. The Last Valois Duke

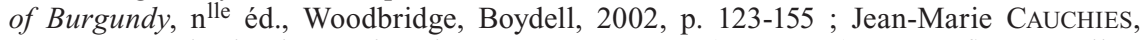
Louis XI et Charles le Hardi : de Péronne à Nancy (1468-1477). Le conflit, Bruxelles, De Boeck, 1996, p. 67-82 ; Henri DuBoIs, Charles le Téméraire, Paris, Fayard, 2004, p. $311-318$. 
pour que leurs ambitions royales se concrétisent enfin ${ }^{(5)}$. Afin de s'assurer la couronne, Philippe met sur pied une expédition qui doit le conduire dans la péninsule Ibérique, par voie de terre, via la France (1501-1503). Au terme de ce périple, il n'est toutefois pas encore roi. Ce n'est qu'après le décès de sa bellemère, Isabelle de Castille (26 novembre 1504), que la couronne lui échoit à Bruxelles, en janvier 1505, avant d'entamer un second périple espagnol qui lui permet de s'affirmer sur ses nouvelles terres... et de trouver la mort, à Burgos, le 25 septembre $1506^{(6)}$. Reine de Castille, son épouse Jeanne demeure dans la péninsule, sous le regard de son père Ferdinand et de Francisco Jiménez de Cisneros ( ca 1436-1517), cardinal-archevêque de Tolède ${ }^{(7)}$. L'émancipation de Charles de Habsbourg (5 janvier 1515) suivie, l'année suivante, du décès de son grand-père Ferdinand d'Aragon (23 janvier 1516) ouvrent à nouveau la voie espagnole. À Bruxelles, le 14 mars 1516, Charles est proclamé roi des Espagnes. Un projet de voyage se forme rapidement. Il s'agit pour Charles de s'imposer dans ses royaumes ibériques et, surtout, d'en écarter son frère cadet Ferdinand, né en Espagne et favori du feu roi d'Aragon. Après plusieurs hésitations, Charles s'embarque à Flessingue (Vlissingen), en Zélande, le 8 septembre 1517, pour un périple de trois années et demie dans ses royaumes espagnols (1517-1520). Il ne quitte finalement la péninsule que le 20 mai 1520 pour se rendre dans l'Empire et coiffer la couronne de roi des Romains ${ }^{(8)}$.

Les trois voyages dont il sera question ici (1501-1503, 1506 et 1517-1520) sont des événements politiques majeurs des règnes de Philippe et de Charles. Ils représentent autant de pas décisifs sur le chemin conduisant la Maison de Bourgogne-Habsbourg au trône royal. Les auteurs qui entouraient les deux souverains l'avaient particulièrement bien compris. Leurs œuvres attestent en effet de la volonté de couler ces princes dans le moule d'une royauté nouvelle, de leur bâtir une identité royale et une légitimité. Toutefois, cette identité ne peut être uniquement bourguignonne. Pour perdurer et assurer à

(5) Ce n'est toutefois qu'après la mort de Juan (4 octobre 1497) et de Miguel (20 juillet 1500), infants d'Espagne, que l'héritage castillan échoira définitivement à Philippe.

(6) Sur l'alliance austro-espagnole et les voyages de Philippe, voir J.-M. CAUCHIES, Philippe le Beau, op. cit., p. 41-54, 135-145 et 176-217 ; Joseph PÉrEZ, Isabelle et Ferdinand. Rois catholiques d'Espagne, Paris, Fayard, 1988, p. 302-304.

(7) José García Oro OFM, "Jiménez de Cisneros, Francisco (Gonzalo) », dans Diccionario biográfico español (= DBE), t. 27, Madrid, Real Academia de la Historia, 2009, p. 804-809 ; Felipe FERNÁNDEZ-ARMESTO, « Francisco Jiménez de Cisneros », dans Peter G. Bietenholz \& Thomas B. Deutscher, eds, Contemporaries of Erasmus, t. 2, Toronto-Buffalo-Londres, University of Toronto Press, 1986, p. 235-237.

(8) Pour un aperçu de ces trois années, sur le plan politique essentiellement, voir P. Chaunu \& M. Escamilla, Charles Quint, op. cit., p. 101-148 ; Raymond Fagel, De Hispano-Vlaamse wereld. De contacten tussen Spanjaarden en Nederlanders, 14961555, Bruxelles-Nimègue, Archives et Bibliothèques de Belgique, 1996, p. 282-293 ; Karl Brandi, Charles Quint, 1500-1558, trad. Guy DE Budé, Paris, Payot, 1939, p. 75-113. Enfin, plus généralement, sur le contexte politique et institutionnel espagnol au début $\mathrm{du} \mathrm{XVI}^{\mathrm{e}}$ siècle, on verra Manuel RIVERo RoDRíGUEZ, « De la separación a la reunión dinástica : la Corona de Aragón entre 1504 y 1516 » et José MARTíneZ MiLláN, « De la muerte del príncipe Juan al fallecimiento de Felipe el Hermoso (1497-1506) », dans José Martínez Millán, ed., La corte de Carlos V, t. 1/1, Madrid, Sociedad Estatal para la Conmemoración de los Centenarios de Felipe II y Carlos V, 2000, p. 45-72 et 73-101. 
Philippe et Charles un avenir ibérique, leur future couronne devait se faire tant bourguignonne qu'espagnole.

Cet article se propose donc d'étudier, dans les sources bourguignonnes écrites sur les voyages de Philippe le Beau et Charles de Habsbourg en Espagne, comment s'élaborent une pensée et un imaginaire de la fonction royale. Il s'agira de montrer comment, sur le plan des idées et représentations politiques, se traduit ce balancement entre tradition et innovation, au cours d'une période de transition pour la dynastie de Bourgogne-Habsbourg ${ }^{(9)}$.

\section{Littérature et voyage}

Les sources utilisées dans cette étude appartiennent toutes, de près ou de loin, à la littérature curiale alors foisonnante dans les Pays-Bas ${ }^{(10)}$. Elles peuvent être séparées en trois groupes : des récits de voyage, autrement dit des textes, principalement en prose, sortis de la plume d'hommes proches du prince et l'ayant accompagné en Espagne ; des chroniques, en prose ou en vers, dans la tradition de celles des indiciaires de Bourgogne, écrites par des auteurs qui n'ont pas mis les pieds en Espagne et qui se servent des récits de voyage comme source première; des pièces de circonstance, soit des œuvres courtes en vers ou en prose, s'employant à décrire un événement particulier (joyeuses entrées, funérailles) en rapport direct avec les voyages espagnols ${ }^{(11)}$.

\section{Récits de voyage}

Les récits de voyage forment le cœur de ce corpus. Il s'agit d'œuvres ayant pour objectif principal de relater le périple ibérique des deux souverains. Ces textes débutent le plus souvent dans les Pays-Bas au moment des préparatifs au voyage, et s'achèvent lorsque le prince et/ou l'auteur quittent le sol espagnol.

(9) Précisons toutefois que les premières relations entre les Pays-Bas et l'Espagne sont bien antérieures aux époques de Philippe le Beau et Charles de Habsbourg. Elles remontent à Philippe le Bon. Sous son règne s'établissent des relations diplomatiques régulières avec toute la péninsule Ibérique, de même que des échanges intellectuels et culturels divers. Voir, en priorité, les articles d'Adeline RUCQUOI, « La Péninsule ibérique et la cour de Bourgogne » et Álvaro FERNÁNDEZ DE CóRDOVA MiRALLES, « L'impact de la Bourgogne sur la cour castillane des Trastamare », dans Werner PARAVICINI, Torsten HILTMANN \& Franck VILTART, eds, La cour de Bourgogne et l'Europe. Le rayonnement et les limites d'un modèle culturel. Actes du colloque international tenu à Paris les 9, 10 et 11 octobre 2007, Ostfildern, Jan Thorbecke, 2013, p. 581-591 et 593-630; et ensuite, pour une vision plus générale, R. Fagel, De Hispano-Vlaamse wereld, op. cit. ; Miguel Ángel EcheVARRíA, Flandes y la monarquía hispánica, 1500-1713, Madrid, Silex, 1998, p. 53-56.

(10) Pour un aperçu général des caractéristiques propres à la littérature bourguignonne sous le règne de Philippe le Beau et le début du principat de Charles Quint, on verra Estelle DOUDET, « Un chant déraciné ? La poésie bourguignonne d'expression française face à Charles Quint ", dans e-Spania. Revue interdisciplinaire d'Études hispaniques médiévales et modernes, en ligne (24 juin 2012), http://e-spania.revues.org/21220 ; DOI : 10.4000/e-spania.21220 (dernière consultation le 5 août 2015).

(11) Ponctuellement, il sera également fait appel à des sources épistolaires tirées des appendices de l'édition des deux voyages de Philippe le Beau (Louis-Prosper GACHARD, ed., Collection des voyages des souverains des Pays-Bas, t. 1, Bruxelles, Commission royale d'Histoire, 1876, p. 341-385 et 491-556). 
Pour le premier voyage de Philippe le Beau (1501-1503), la principale source est le Voyage de Philippe le Beau en Espagne ${ }^{(12)}$ d'Antoine de Lalaing (1480-1540), sire de Montigny, et fils de Josse de Lalaing, un ancien conseiller et chambellan de Charles le Téméraire. Dans les années qui suivront ce voyage, Antoine deviendra un personnage très influent de l'entourage de Marguerite d'Autriche et de Charles Quint. Il sera fait, entre autres, chevalier de la Toison d'Or en 1516, et comte de Hoogstraten en $1518^{(13)}$. Très précis, Lalaing décrit chaque étape de la cour depuis son départ des Pays-Bas, s'attachant tout particulièrement à présenter, outre les événements politiques, les particularités de la culture nobiliaire et des mœurs espagnoles.

Un texte comparable à celui de Lalaing existe pour le second voyage de Philippe le Beau en $1506^{(14)}$. Certains y reconnaissent d'ailleurs la plume de Lalaing, mais une telle attribution demeure incertaine. Des différences importantes peuvent en effet être observées entre les deux textes (l'auteur se concentre sur les événements politiques et non sur les lieux qu'ils visitent comme le faisait Lalaing), de même que des convergences (entre autres du point de vue des valeurs politiques). Par mesure de précaution, nous préférerons parler de l'« auteur anonyme » du récit de 1506, plutôt que d'attribuer le texte à Lalaing.

La chronique rimée ${ }^{(15)}$ de Nicaise Ladam $(1465-1547)^{(16)}$ peut également être considérée comme un récit de voyage puisque l'auteur suivit Charles dans

(12) Antoine De Lalaing, Voyage de Philippe le Beau en Espagne, dans L.-Pr. GACHARD, ed., Collection des voyages, op. cit., t. 1, p. 121-385.

(13) Sur ce personnage et sa chronique, on verra J.-M. Cauchies, Philippe le Beau, op. cit., p. 136, 178 n. 93, 180-181 ; ID., " Lalaing, Antoine de », dans DBE, t. 28, 2009, p. 679-680 ; Hans Cools, Mannen met macht. Edellieden en de moderne Staat in de Bourgondisch-Habsburgse landen (1475-1530), Zutphen, Walburg Press, 2001, p. 63-65 et 243-245; Louis-Prosper GACHARD, Introduction, dans ANTOINE DE LALAING, Voyage, op. cit., p. XIV-XVIII ; Jozef LAUWERYS, " Lalaing, Antoon van », in Nationaal biografisch woordenboek, t. 1, Bruxelles, Koninklijke Academie van België, 1964, col. 653-660 ; Tania VAN HEMELRYCK, «Antoine de Lalaing. Récit du premier voyage de Philippe le Beau en Espagne ", dans Bernard Bousmanne, Hanno WiJsman \& Sandrine Thieffry, eds, Philippe le Beau (1478-1506). Les trésors du dernier duc de Bourgogne, Bruxelles, Bibliothèque royale de Belgique, 2006, p. 87-89.

(14) Deuxième voyage de Philippe le Beau en Espagne, en 1506, dans L.-Pr. GaChard, ed., Collection des voyages, op. cit., t. 1, p. 387-556. Sur l'identification de l'auteur et son texte, voir J.-M. CAUCHIES, Philippe le Beau, op. cit., p. 180-181 ; L.-Pr. GACHARD, Introduction, op. cit., p. XVIII-XXVII.

(15) La chronique n'existe que sous forme manuscrite. Claude THIRY, Introduction, dans Nicaise Ladam, Mémoire et épitaphe de Ferdinand d'Aragon, ed. Claude ThiRY, Paris, Les Belles Lettres, 1975, p. 33-35, présente les qualités et les défauts de chaque copie. Pour notre part, nous avons choisi d'utiliser la version de Bruxelles, Bibliothèque royale de Belgique (= KBR), ms. 14864-14865, qui, chez Thiry est considérée à égale valeur avec le manuscrit de Courtrai (Centrale Bibliotheek, ms. 89). D’une manière générale, sur la production manuscrite et imprimée de Ladam, on verra Cl. THIRY, Introduction, op. cit., p. 26-36 ; Bibliotheca Belgica. Bibliographie générale des Pays-Bas, ed. Ferdinand VAN DER HAEGHEN, reed. Marie-Thérèse LengeR, t. 3, Bruxelles, Culture et Civilisation, 1964, p. 627-641.

(16) Nous suivons la biographie dressée par Cl. THIRY, Introduction, op. cit., p. 1526 ; ainsi que Jacques-Charles LemAIRE, « Le Mémoire de l'Aigle et de la Salamandre de Nicaise Ladam, roi d'armes de Charles Quint ", dans André TouRnEuX, ed., Liber amicorum Raphaël de Smedt, t. 4, Litterarum Historia, Louvain, Peeters, 2001, p. 75-98. Dans un second temps, on se référera aux travaux suivants, dont Thiry montre clairement les limites 
la péninsule entre 1517 et 1520 . Rien n'est certain en ce qui concerne les voyages de Philippe le Beau, même si l'auteur affirme y avoir participé(17). Natif de Béthune ${ }^{(18)}$, Ladam entame son œuvre dès 1488 avec pour objectif de magnifier les souverains des Pays-Bas. C'est d'ailleurs probablement à cette époque qu'il entre à leur service. Il apparaît en 1506 sous le pseudonyme $\mathrm{du}$ « Songeur » ${ }^{(19)}$. À partir de 1516, on le retrouve chevaucheur ordinaire de l'écurie de Charles de Habsbourg, et serviteur de Ferry de Croÿ († 1524), seigneur du Roeulx ${ }^{(20)}$, l'un des principaux conseillers de Philippe puis de Charles. Il occupe ensuite les fonctions d'héraut d'armes (Béthune) entre 1519 et 1522, puis de roi d'armes (Grenade), probablement entre 1522 et $1526^{(21)}$. L'aspect encomiastique l'emporte sur le reste puisqu'il s'emploie à décrire avec emphase et dans le détail les honneurs que reçoivent ses maîtres, sans élaborer d'images ou de symbolique du pouvoir spécifiques.

La source principale du voyage de Charles est le Premier voyage de Charles Quint en Espagne composé par Laurent Vital ${ }^{(22)}$. Ce chroniqueur, originaire de Flandre française (région de Lille ?), entama sa carrière au service de Jean de Luxembourg ( $c a$ 1477-1508), seigneur de Ville ${ }^{(23)}$, puis, dès 1508, en tant que valet de chambre de Charles de Habsbourg ${ }^{(24)}$. Participant au

en ce qui concerne Ladam : S.D. (sic), « Ladam (Nicaise, dit le Songeur) », dans Georges GRENTE \& Michel SimOnin, eds, Dictionnaire des Lettres françaises. Le XVI siècle (= DLF XVI $\left.{ }^{e}\right)$, rééd., Paris, Fayard, 2001, p. 662 ; Émile VAN ARENBERGH, « Ladam », dans Biographie nationale de Belgique, t. 11, Bruxelles, Bruylant, 1890-1891, col. 15-21.

(17) Ladam est absent des comptes de l'Hôtel pour cette période (Ordonnance de Philippe le Beau pour la composition et le gouvernement de sa maison pendant son voyage d'Espagne : ${ }^{e r}$ novembre 1501, dans L.-Pr. GACHARD, ed., Collection des voyages, op. cit., t. 1, p. 345-372 ; Rôle des officiers de la maison de Philippe le Beau au 8 juin 1506, ibid., t. 1, $\mathrm{n}^{\mathrm{o}} 21, \mathrm{p}$. 524-533). Par contre, on le retrouve dans l'ordonnance de la cour de Charles Quint en 1517, en tant que poursuivant d'armes (ed. Raymond FAGEL, « Het Bourgondische hof van Karel V als koning van Spanje. De hofstaat van 21 juni 1517 », dans Bulletin de la Commission royale d'Histoire, t. 180, 2014, p. 69-137 [ici p. 125]).

(18) France, rég. Nord-Pas-de-Calais, dpt Pas-de-Calais, ch.-1. arr.

(19) Ladam ne recevra jamais le titre d'indiciaire, qui échoira, à la mort de Molinet, à Jean Lemaire de Belges, puis dès 1511, à Rémi Dupuys (E. DoudET, « Un chant déraciné ? », op. cit., p. 7 ; Anne Schoysman, La Chronique de Jean Lemaire, dans JeAN Lemaire De Belges, Chronique de 1507, ed. Anne Schoysman, notes et index JeanMarie CAUChiEs, Bruxelles, Académie royale de Belgique, 2001, p. 14).

(20) Sur ce personnage, également chevalier de la Toison d'or et chambellan de l'Hôtel, voir H. Cools, Mannen met macht, op. cit., p. 193-194 ; Gérard MOREAU, « Ferry de Croy ", dans P.G. Bietenholz \& Th.B. Deutscher, eds, Contemporaries of Erasmus, op. cit., t. 1, 1985, p. 365-366. Ladam semble par ailleurs recevoir une pension de la régente Marguerite dès 1511 (Jean MiCAUlt, Compte du ler janvier 1511 au 31 décembre 1511, Lille, Archives départementales du Nord (= ADN), Recette générale des Finances, B 2221.

(21) Sa chronique, fort appréciée du prince, participe de son ascension sociale. En 1517, peu avant le début du voyage, il est en effet récompensé pour celle-ci de 121.10 sols (JeAn MiCault, Compte du $1^{e r}$ janvier 1517 au 31 décembre 1517, Lille, ADN, Recette générale des Finances, B 2267, fol. 247r).

(22) On s'étonne toutefois de constater que les comptes des Hôtels de Philippe et de Charles ne le mentionnent pas durant les voyages.

(23) Sur ce conseiller fort important de Philippe le Beau, chambellan de ce prince et chevalier de la Toison d'or, voir J.-M. CAUChIES, Philippe le Beau, op. cit., surtout p. 62 ; H. CoOLs, Mannen met macht, op. cit., p. 259-260.

(24) Ses qualités littéraires et dramaturgiques sont appréciées à la cour puisque, cette

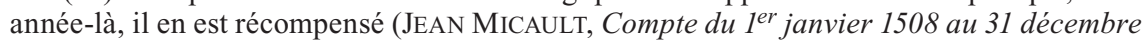


voyage de son maître en Espagne, il est contraint de reprendre la mer pour les Pays-Bas, en 1518, dans la suite de Ferdinand de Habsbourg. Il semblerait que le chroniqueur soit toujours vivant autour de l'année 1525, mais on perd ensuite sa trace ${ }^{(25)}$. Vital est un témoin de tout premier ordre, tant par le soin qu'il prend de recueillir les informations et de rendre compte de ses impressions personnelles, que par ses nombreux centres d'intérêt (politique, cérémoniel, mœurs et traditions). Il pourrait ainsi être comparé à cette sorte de chroniqueur-« reporter de guerre » qu'est son contemporain, le Français Jean d'Auton (ca 1466/1467-1528) ${ }^{(26)}$.

\section{Chroniques bourguignonnes}

Les Chroniques de Jean Molinet (1435-1507) ${ }^{(27)}$ peuvent à juste titre être considérées comme le modèle même de la chronique bourguignonne. Tout d'abord assistant de George Chastelain, Molinet accède au titre d'indiciaire de Bourgogne à la mort de son maître en 1475. Certes, la qualité de son témoignage est moindre en ce qui concerne les événements propres à nos voyages puisqu'il n'a pas participé aux expéditions de Philippe le Beau - il puise donc abondamment dans Lalaing et le Deuxième voyage - et qu'il est mort avant que Charles n'entame son périple. L'intérêt du texte repose surtout sur le fait que Molinet, en chroniqueur officiel de la Maison de BourgogneHabsbourg, développe un imaginaire politique tout à fait foisonnant, sans égal. Il glorifie son prince et sa Maison, sans pour autant perdre son sens critique. Il se fait ainsi le chantre d'un « pacifisme " qu'il s'efforce d'inculquer à Philippe en le présentant, dans ses Chroniques, comme le champion de la paix, notamment en tissant des liens entre le Bourguignon et sa belle-mère Isabelle la Catholique ${ }^{(28)}$.

1508, Lille, ADN, Recette générale des Finances, B 2207, fol. 288r).

(25) Plus généralement, sur le personnage, on se reportera à Charles PIOT, Introduction, dans Laurent Vital, Premier voyage de Charles Quint en Espagne, de 1517 à 1518, dans L.-Pr. GaChard, ed., Collection des voyages, op. cit., t. 3, 1881, p. IV-V, et, mais avec prudence, au travail de Alfred DE RIDDER, Un chroniqueur du XVI esiècle, Laurent Vital. Essai critique, Gand, S. Leliaert, A. Siffer et c ${ }^{\text {ie }}$, 1888.

(26) Sur ce dernier, voir Étienne VAuCHERET, Art. " Auton (Jean d') », dans G. GRENTE \& M. SimOnin, eds, $D L F X V I^{e}$, p. 91-92 ; Jonathan DumONT, « Ordre social et destin impérial dans les Chroniques de Louis XII de Jean d'Auton ", dans Bibliothèque d'Humanisme et Renaissance, t. 69, 2007, p. 589-613.

(27) Jean Molinet, Chroniques, ed. George Doutrepont \& Omer Jodogne, t. 2, Bruxelles, Palais des Académies, 1935. Pour une biographie du personnage, nous renvoyons le lecteur à Noël DUPIRE, Jean Molinet, la vie, les oeuvres, Paris-Genève, Droz, 1912, et ensuite à Sylvie LefÈvre, "Jean Molinet », dans Georges Grente, Robert Bossuat, Louis Pichard, Guy Raynaud de Lage, Geneviève Hasenohr \& Michel ZINK, eds, Dictionnaire des Lettres françaises. Le Moyen Âge, $\mathrm{n}^{1 \mathrm{le}}$ éd., Paris, Fayard, 1992, p. 821-823.

(28) Sur Molinet, son écriture de l'histoire et sa pensée politique, voir en priorité Jean DevauX, Jean Molinet, indiciaire bourguignon, Paris, Honoré Champion, 1996 ; Philippe FRIEDEN, La Lettre et le miroir. Écrire l'histoire d'actualité selon Jean Molinet, Paris, Honoré Champion, 2013 ; ainsi que Jean Devaux, Estelle Doudet \& Élodie LecupPreDeSJARDIn, eds, Jean Molinet et son temps. Actes des rencontres internationales de Dunkerque, Lille et Gand (8-10 novembre 2007), Turnhout, Brepols, 2013. 
La Bibliothèque royale de Belgique possède trois autres chroniques à première vue fort intéressantes. Il s'agit du texte de Julien Fossetier, poète originaire d'Ath, attaché à Marguerite d'Autriche ${ }^{(29)}$. L'œuvre se révèle cependant être un résumé peu inspiré du Premier voyage d'Antoine de Lalaing. Les deux autres chroniques concernent le périple de Charles. La première est due à la plume de Rémi Dupuys ${ }^{(30)}$, indiciaire de Bourgogne dès 1511, en remplacement du célèbre Jean Lemaire de Belges, parti servir la reine Claude de France ${ }^{(31)}$. Rédigée en vers, elle prend surtout la forme d'une allégorie à la gloire du prince, très semblable au Séjour d'honneur du Français Octovien de Saint-Gelais ${ }^{(32)}$. Les événements servent de trame sur laquelle l'auteur tisse un propos où les considérations politiques sont malheureusement trop rares pour être exploitées dans le cadre de cette étude. Enfin, il y a les Mémoires des voyages de l'empereur Charles Quint de Jean de Vandenesse (Van de Nesse), contrôleur des finances, au service de l'empereur jusqu'en $1551^{(33)}$. La chronique débute en 1514 et couvre la plupart des voyages de Charles, mais n'aborde que brièvement son premier séjour espagnol. L'œuvre n'est pas inintéressante, mais trop courte, sur notre période, pour mériter de longs commentaires. On l'aura donc compris, pour des raisons diverses, ces trois textes ne pourront constituer, dans le cadre de cette étude, des sources de premier plan.

(29) Sur Fossetier, on verra surtout Jacques-Charles LEMAIRE, « Julien Fossetier, poète athois thuriféraire de Charles Quint », dans Bulletin de la Classe des Lettres de l'Académie royale de Belgique, 6 ${ }^{\mathrm{e}}$ s., t. 12, 2001, p. 287-316 ; ID., « Julien Fossetier, poète d'Ath, rhétoriqueur et humaniste ", dans Bulletin bimestriel du Cercle royal d'Histoire et d'Archéologie d'Ath, t. 207, 2002, p. 625-633, et ensuite Auguste VANDER MEERSCH, Art. «Fossetier (Julien) », dans Biographie nationale de Belgique (= BNB), t. 7, Bruxelles, Bruylant, 1883, col. 203-204 ; ainsi que L.-Pr. GACHARD, Introduction, op. cit., p. XVII, pour une comparaison entre ce récit et celui de Lalaing.

(30) RÉMI DuPUYS, S'ensuyt une description poétique confirme à la vraye hystoire $d u$ voyage de très-hault, très-puissant et très rédoubté prince Don Charles, par la grâce de Dieu, Roy Katholique, depuis le 6 septembre 1517, au moment de l'embarquement, Bruxelles, KBR, ms. 10489, ff. 51r-75r. Sur celui-ci, voir Auguste VANDER MEERSCH, « Du Puys (Remi) », dans BNB, t. 6, 1878, col. 326-328; ainsi que R. FAGEL, « Het Bourgondische hof van Karel V », p. 130.

(31) Dans le Registre des mandemens qui ont estez veriffiez, deppuis le premier de febvrier $X^{c}$ dix jusques au $X X I^{e}$ de mai, $X V^{C} X I$, Lille, ADN, Recette générale des Finances, B 2222, fol. 108r-v, Dupuis est mentionné comme indiciayre et historiographe de l'Empereur et de monseigneur l'archiduc. Ce n'est pourtant que dans un compte de l'année 1512 qu'il est nommément désigné comme remplaçant de Jean Lemaire de Belges (Lettres de commission de Maximilien, empereur, de Charles, archiduc d'Autriche, et de Marguerite,

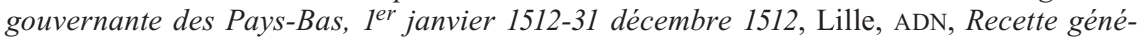
rale des Finances, B 2226. En 1513, il commence à recevoir des gages en tant qu'indiciaire et historiographe de l'archiduc et de l'archiduchesse (Mandements de Marguerite d'Autriche, gouvernante des Pays-Bas, au sujet de sommes payées pour services rendus, gages, travaux et dons. 23 mai 1513-17 octobre 1515, Lille, ADN, B 2230, ff. 50v-51r).

(32) Le texte, s'insérant dans le contexte des préparatifs puis de la campagne d'Italie de Charles VIII, a été composé entre 1489 et 1494 (voir l'édition de Frédéric DuvaL, Genève, Droz, 2002).

(33) Jean de VAndenesse (VAn De Nesse), Journal des voyages de Charles-Quint de 1514 à 1551, dans L.-Pr. GACHARD, ed., Collection des voyages, op. cit., t. 2, 1874, p. 57-62 (sur les années 1517-1520). Le manuscrit original semble être le Bruxelles, KBR, ms. 14522 . 


\section{Pièces de circonstance}

Plusieurs pièces de circonstance ont été composées avant, durant ou directement après les séjours de Philippe et de Charles en Espagne. La plupart de ces textes sont dus à un trio formé de Jean Molinet, Nicaise Ladam et Rémi Dupuys ${ }^{(34)}$. Leur intérêt réside de notre point de vue dans le fait que ces pièces complètent les récits de voyage en se concentrant soit sur des événements spécifiques, soit directement sur l'image royale de Philippe et de Charles.

Jean Molinet est certainement celui qui contribue le plus à cette partie du corpus. Dans L'alliance matrimoniale des enfans d'Austrice et d'Espaigne ${ }^{(35)}$, il chante les louanges du double mariage austro-espagnol de Malines, le 5 novembre 1495, entre, d'une part, Philippe le Beau et Jeanne de Castille, et, d'autre part, Marguerite d'Autriche et Juan, infant d'Espagne et héritier des Rois catholiques. La pièce aurait été écrite au moment des épousailles de Philippe et de Jeanne à Lierre (20 octobre 1496), en tout cas avant le décès de Juan le 4 octobre 1497. Molinet aborde ensuite le premier voyage de Philippe dans plusieurs pièces : une Lettre a monseigneur l'archiduc qui évoque le départ du souverain en 1501, Le voyage d'Espaigne probablement écrit au retour de Philippe en 1503, une Ballade touchant le voyaige d'Espaigne difficilement datable ( $c a$ novembre 1501-avril 1503), ainsi qu'une Ballade adreschant a messeigneurs de Fois, Monpensier et Vendosme composée après le retour de Philippe puisqu'elle loue les mérites des seigneurs français envoyés par Louis XII en tant qu'otages à Valenciennes afin de garantir le retour de l'archiduc dans les Pays-Bas via la France ${ }^{(36)}$. Deux autres textes, Coeurs vertueux et l'Epytaphe de dame Ysabeau rö̈ne de Castille, évoquent le décès de la reine Isabelle (26 novembre 1504) tout en célébrant les nouveaux souverains Philippe et Jeanne ${ }^{(37)}$. Molinet traite du voyage de 1506 dans Les regrés de la mort Philippes, roy de Castille, pièce composée suite au décès du souverain à Burgos le 25 septembre $1506^{(38)}$.

(34) Ce recours au prosimètre est tout à fait caractéristique de l'école dite des Rhétoriqueurs - à laquelle sont associés ces auteurs - qui, par des « expérimentations graphiques, verbales et sonores " variées, entend avant tout célébrer le pouvoir princier (voir le collectif Le prosimètre à la Renaissance, dans Cahier V.L. Saulnier, t. 22, 2005, et ensuite, François Rigolot, "Rhétoriqueurs », dans G. GRENTE \& M. Simonin, eds, DLF XVI , p. 1015-1018 [p. 1015 pour la citation]; Paul ZuMTHOR, Le Masque et la lumière. La poétique des grands rhétoriqueurs, Paris, Seuil, 1978).

(35) JEAN MOLINET, L'alliance matrimoniale des enfans d'Austrice et d'Espaigne, dans ID., Les Faictz et Dictz, ed. Noël DupIRE, t. 1, Paris, Société des anciens Textes français, 1936, no 26, p. 335-340.

(36) Respectivement, ID., Lettre a monseigneur l'archiduc quand il alla en Espaigne, ibid., $\mathrm{n}^{\mathrm{O}}$ 36, p. 371-372 ; ID., Le voyage d'Espaigne, ibid., $\mathrm{n}^{\circ}$ 37, p. 373-380 ; ID., Ballade touchant le voyaige d'Espaigne, ibid., $\mathrm{n}^{\mathrm{o}} 38$, p. 381-382 ; ID., Ballade adreschant a messeigneurs de Fois, Monpensier et Vendosme, ibid., no 42, p. 392-393.

(37) ID., Coeurs vertueux, ibid., t. 1, no 41, p. 389-391 (pour cette pièce, l'éditeur, N. Dupire, avance la date de 1503, ce qui est impossible, vu qu'elle mentionne le décès de la reine de Castille) ; ID., Epytaphe de dame Ysabeau roÿne de Castille, ibid., nº 45, p. 401-406.

(38) ID., Les regrés de la mort Philippes, roy de Castille, dans ID., Les Faictz et Dictz, t. 1, n ${ }^{\circ} 17$, p. 410-417. Pour des considérations stylistiques et contextuelles substantielles sur ces textes, on pourra consulter J. DevauX, Jean Molinet, op. cit., p. 515-516 et 586587 ; Ph. FRIEDEN, La lettre et le miroir, op. cit., p. 112-114 et 296. 
Nicaise Ladam retiendra notre attention en raison de plusieurs pièces qu'il a consacrées à la mort de l'archiduc Philippe ${ }^{(39)}$. Celle qui nous occupera en priorité s'intitule le Mémoire et Epitaphe de Ferdinand d'Aragon. Composé peu après la mort du souverain aragonais le 23 janvier 1516, il s'agit d'un panégyrique en l'honneur du roi défunt et de son successeur, Charles de Habsbourg (40).

Évoquons, enfin, Les exeques et pompes funerale de feu deternelle et tresglorieuse memoire Don Fernande roy catholicque de Rémi Dupuys. L'auteur y relate la cérémonie funèbre organisée à Bruxelles en l'honneur de Ferdinand d'Aragon les 14 et 15 mars 1516. Dupuys s'attarde longuement sur la symbolique déployée lors de l'événement, ce qu'aucun autre auteur ne fait avec autant de détails ${ }^{(41)}$.

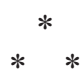

Rappelons que les textes qui forment ce corpus seront avant tout envisagés pour les interprétations politiques et symboliques que les auteurs donnent des événements. Nous ne pourrons toutefois pas rendre compte dans ces pages de l'ensemble de leurs idées politiques ${ }^{(42)}$. Nous nous concentrerons

(39) Ces pièces, au nombre de trois, sont contenues dans les manuscrits Bruxelles, KBR, 14864-14865, f. 69r-70r et Valenciennes, Bibliothèque municipale, 661, f. 8rb-10rb. Elles ont été éditées par Claude THIRY, Recherches sur la déploration funèbre française à la Renaissance, t. 2 : Recueil de textes, Université de Liège, Thèse de doctorat inédite, 1972-1973, p. 258-268. Toutefois, si l'on excepte le Mémoire et Epitaphe, elles ne présentent que peu d'éléments de nature politique. Nous n'y recourons pas dans les pages qui suivent.

(40) NicAise LADAM, Mémoire et épitaphe, op. cit. (voir supra, n. 15).

(41) RÉMI DUPUYs, Les exeques et pompes funerale de feu deternelle et tresglorieuse memoire don Fernande roy catholicque faicte et acomplie en l'Eglise saincte Goule à Bruxelles le vendredi XIIII de mars quinze centz et quinze par la serenissime haultesse de tres excellant tres puissant et tres redoubte prince don Charles son heritier, et ores par la grace de dieu roy catholique, Louvain, Thierry Martens, 1516 (Bruxelles, KBR, VH 26. 132 A). Cet auteur s'illustre aussi par un récit de l'entrée de Charles à Bruges en 1515 : ID., $L a$ tryumphante et solemnelle entree faicte sur le nouvel et joyeux advenement de tres hault, tres puissant et tres excellent prince Monsieur Charles prince des Hespaignes, archiduc d'Austrice, duc de bourgongne, comte de Flandres, etc., en sa ville de Bruges l'an mil. V. cens et. XV. Le XVIII jour d'apvril apres Pasques (Paris, Gilles de Gourmont, 1515 ; Bruxelles, KBR, VH 27 574, $\mathrm{n}^{\text {lle }}$ cote B 1553. Un manuscrit existe à Vienne, Österreichische Nationalbibliothek, Cod. 2591. Nous préparons en ce moment une étude sur ces pièces. Les premiers résultats (« Rémy Dupuis. Un chroniqueur publiciste dans les premières années du règne de Charles Quint ») seront disponibles dans les actes de la journée d'études $C y$ commence ung livre emprainté... Diffusion et réception de la littérature médiévale en langue française par l'imprimerie (1470-1550), Université de Liège, 17 mai 2016.

(42) Si ce n'est dans certaines études littéraires (J. DevauX, Jean Molinet, op. cit. ; $\mathrm{Ph}$. FRIEDEN, La lettre et le miroir, op. cit., par exemple) ou celles d'historiens mettant en évidence la dimension touristique et culturelle de ces textes (Bethany ARAM, « Voyages from Burgundy to Castille : Cultural Conflict and Dynastic Transitions, 1502-06 », dans Joan Lluís PAlOS \& Magdalena SÁNCHEZ, eds, Early Modern Dynastic Marriages and Cultural Transfer, Farnham, Ashgate, 2016, p. 91-114 ; José Manuel CALDERÓN ORTEGA, «El viaje de Felipe el Hermoso a España en 1502 », dans Manuel CRIADO DE VAL, ed., Camineria hispánica. Actas del II Congreso Internacional de Caminería Hispánica, t. 2, Guadalajara, 1996, p. 321-332 ; Raymond FAGEL, «El descubrimiento de España 
donc sur trois aspects qui nous semblent à la fois prépondérants et liés à l'élaboration de l'image royale de Philippe et Charles. Dans un premier temps, nous aborderons les enseignements politiques que les auteurs tirent de leur expérience espagnole et qu'ils transmettent à leurs lecteurs et auditeurs, un public composé en priorité des membres de la cour des Pays-Bas, voire du prince lui-même ${ }^{(43)}$. Dans le second point, nous aborderons la tendance qu'ont les auteurs à rapprocher les Rois catholiques et les princes de la Maison de Bourgogne-Habsbourg en magnifiant leurs liens familiaux et dynastiques, de manière à installer Philippe et Charles dans une dignité royale. Mais pour être pleinement reconnus comme souverain nos deux princes doivent obtenir l'assentiment des forces vives de leurs royaumes ibériques. Leurs voyages en terres espagnoles visent précisément à gagner un tel soutien. Ainsi, dans

a través de los relatos de viaje de Antoine de Lalaing y Laurent Vital », dans JeanMarie CAUChiEs, ed., Diplomates, voyageurs, artistes, pèlerins, marchands entre pays bourguignons et Espagne aux XV et XVI siècles. Rencontres de Madrid-Tolède (23 au 26 septembre 2010), Publication du Centre européen d'Études bourguignonnes (XIV $X V I^{e}$ siècle) $(=P C E E ́ B)$, t. 51, 2011, p. 147-162), le corpus envisagé ici est généralement étudié du point de vue de l'histoire événementielle - lecture nécessaire mais qui ne rend pas tout à fait justice à ces textes (voir à ce propos l'utilisation tout à fait exemplaire que K. BRANDI, Charles Quint, op. cit., p. 72-78, fait de la chronique de Laurent Vital). Si l'on regarde au-delà de ce corpus, on découvre des études sur la pensée politique influencée par les voyages espagnols de Philippe et de Charles. Toutefois, l'approche retenue est souvent celle d'une opposition entre, d'une part, les souverains et leur personnel bourguignon, et, d'autre part, la noblesse castillane et les Cortès (voir John H. ELLIOTT, Imperial Spain, 1469-1716, Londres, Edward Arnold Publ., 1963, p. 125-135 ; Jose Antonio FERNÁNDEZSantamaria, The State, War and Peace. Spanish Political Thought in the Renaissance, 1516-1559, Cambridge, Cambridge U.P., 1977, p. 11-34). Il faut toutefois reconnaître que la pensée politique du règne de Philippe le Beau demeure mal connue, même si le travail de J.-M. CAUChiEs, Philippe le Beau, op. cit., p. 3-23 (surtout) et Hanno WiJSMAN, « L'otage de Gand. La formation d'un jeune prince », dans B. Bousmanne, H. WiJsman \& S. ThIEFfry, eds, Philippe le Beau (1478-1506), op. cit., p. 23-30, permettent de s'en faire une idée. En ce qui concerne Charles de Habsbourg, les connaissances sont plus solides (Juan Carlos D'AMico, Charles Quint maître du monde : entre mythe et réalité, Caen, P.U. de Caen, 2004 ; Frances A. YATES, Astrée. Le symbolisme impérial au XVIe siècle, trad. Jean-Yves Pouilloux \& Alain Huraut, Paris, Belin, 1989, p. 17-56), mais en la matière la bibliographie a souvent tendance à négliger la première partie de son règne pour se concentrer sur l'après élection impériale.

(43) Antoine De Lalaing, Voyage, op. cit., p. 123-124, écrit pour illustrer les œuvres vertueuses de Philippe le Beau ainsi que les paix et submissions et traictiés qu'il procura entre pluseurs roys et princes, come on voidt en croniques modernes. LAURENT VITAL, Premier Voyage, op. cit., p. 1-2, veut parler de l'honneur et triumphe d'iceluy mon trèsredoubté seigneur et prince souverain, Charles d'Austrice [...], tant de sa félicité que de plusieurs aultres besongnes, au plus près de la vérité qu'il me serat possible [...] afin de aulcunement apaisier ou aulcunement adouchir [les] piteuses complainctes et lamentations [des sujets des Pays-Bas], et leur donner quelque consolation après le départ du prince. Le prologue des Chroniques de Jean Molinet ayant été écrit à l'époque de Charles le Téméraire il ne nous renseigne pas sur le sens précis que l'indiciaire entend donner aux voyages de Philippe le Beau, même si le souci d'honorer en général la Maison de Bourgogne traverse toute son œuvre (JEAN Molinet, Chroniques, op. cit., t. 1, p. 25-28). De même, chez Ladam, si les motivations sont moins évoquées, il est clair qu'il entend glorifier ce sang d'Austrice comme le premier et certain successeur et vray possesseur de la Castille (NicAise LADAm, Mémoire, op. cit., p. 89, v. 24-26). Chez tous les quatre, la dimension encomiastique se mêle à une volonté de transmettre et d'apprendre à leur public. 
notre troisième point, nous examinerons comment s'élabore un discours sur l'accueil réservé aux princes austro-bourguignons par la noblesse et les Cortès d'Espagne.

Par ces trois points, nous ambitionnons donc de rendre compte de l'influence des voyages espagnols de Philippe le Beau et Charles Quint sur la pensée politique dans les Pays-Bas, et ce par le biais de sources qui n'ont que trop rarement été lues dans ce sens.

\section{Découvrir et connaître ses royaumes}

Dans leurs œuvres, les chroniqueurs et poètes qui entourent les princes austro-bourguignons partagent leur découverte de l'Espagne, et ce faisant transmettent des informations clés et parfois des avis sur la situation politique des royaumes ibériques, informations et conseils de nature à aider le souverain à gouverner. Ce niveau de lecture, celui qui, pour ainsi dire, saute aux yeux, peut-être décomposé en trois strates : des informations issues de l'observation de la nature, des mœurs des Espagnols et du milieu urbain.

\section{La nature}

Lévocation de la nature est permanente dans les sources de ce corpus. Toutefois, la plupart du temps, la faune et la flore n'offrent pas nécessairement de cadre à la réflexion politique. Chez Laurent Vital, par exemple, on constate une curiosité quasi naturaliste pour les particularités de la faune et de la flore d'Espagne $^{(44)}$. Il en va de même chez Antoine de Lalaing qui s'émerveille à la vue des jardins, des fleurs et des fruits exotiques de Castille et d'Andalousie ${ }^{(45)}$. L'un comme l'autre font simplement montre d'une grande curiosité.

Il faut lire Jean Molinet pour trouver une interprétation politique de la nature espagnole. Chez lui, cette dernière permet de construire un discours

(44) L'auteur établit par exemple de très nombreuses comparaisons entre la faune et la flore d'Espagne et des Pays-Bas. Arrivé dans le golfe de Biscaye, il s'interroge sur la couleur de l'eau de mer, laquelle je trouvay, en allant, estre de diverses couleurs. Depuis la Zélande, jusque Calais, elle est blanchastre, un petit sur le vert, puis, plus alloient en advant et plus estoit clère et verde, et, enfin, une fois arrivé à la mer d'Espaigne, elle devient plus clère que devant, en tirant sur le bleu (LAURENT VITAL, Premier voyage, $o p$. cit., p. 72-73). Après l'eau, il évoque les poissons, comparés de la même manière à ceux des Pays-Bas (ibid., p. 73 et 113). Vital cherche à appréhender la nature espagnole en la rapprochant de celle qu'il connaît. Certains lieux sont ainsi décrits par le biais d'une analogie, tels le jardin de l'évêque de Valladolid qu'on ne [...] sçaroye myeulx comparer que à la rue du Mynne-Watter à Bruges (ibid., p. 255) ou un mont, près de Tordesillas, comme on diroit par dechà le Mont de la Trinité auprès de Tournay (ibid., p. 148 : il s'agit de l'actuel Mont-Saint-Aubert à Tournai).

(45) Il en est ainsi du jardin du roi à Tolède, plain d'orengiers, de grenadiers et aultres arbres fructueuses (ANTOINE DE LALAING, Voyage, op. cit., p. 177), de même qu'à Séville ou encore à Grenade (ibid., p. 202-203 et 204). Parfois, son intérêt se porte aussi sur la faune, comme la ménagerie du château de Benavente (com. aut. Castille-et-León, prov. Zamora, comarque de Benavente), pleine de léons et lupars (ibid., p. 161-162), faune certes importée dans ce cas précis. 
encomiastique centré autour de la personne de Philippe le Beau. Dans Le voyage d'Espaigne, Molinet évoque le cler souleil, ainsi que maint pastour [...] / Mainte champaigne ${ }^{(46)}$ de Castille, afin de vanter les mérites d'une terre sur laquelle son maître est appelé à régner. La nature est ici tout à fait politisée. On s'en rend particulièrement compte à travers le thème du jardin ou du verger, évocation poétique de l'État. Dans L'alliance matrimoniale, Molinet présente les différents royaumes auxquels Philippe pourrait s'allier par mariage comme plusseurs / Vergiers fort seurs ${ }^{(47)}$, que surpasse toutefois l'Espagne :

Espaigne avoit arbres, estocqs, plantis,

Champs, pretz, pastis et noble germinade,

Figues, roisins, vins et vivres exquis;

Se avoit conquis sus mescreans mauldis

Les fors taudis de la noble Grenade,

Qui donne rude allegance ou malade,

Mieux que salade, herbe ou quelque rachine:

Moult vault le grain qui porte medechine ${ }^{(48)}$.

Le prince, lui-même, est intégré à cette métaphore végétale puisqu'il est un bouton de grand bonté qui Sera bouté en ung beau jennetier / Et de Castille ung prince redoubté(49), tandis que les Pays-Bas sont le terroy de Bourgongne, une terre bien labouree par le gardinaige du filz d'imperateur romain ${ }^{(50)}$. Les Pays-Bas donnent, en quelque sorte, l'exemple de ce que pourrait devenir l'Espagne, pays aux richesses naturelles abondantes mais mal exploitées, sous le gouvernement de Philippe le Beau ${ }^{(51)}$. L'évocation de la nature permet à Molinet de souligner les qualités du gouvernement du prince et le futur radieux qu'il apportera à ses territoires ibériques ${ }^{(52)}$.

\section{Coutumes, pratiques et mours}

De l'observation de la nature, on en vient à celle des mœurs espagnoles, sujet bien plus fécond en considérations politiques. On rencontre, dans certains de nos textes, une volonté de décrire les habitudes, les comportements et le caractère - parfois supposé - des Espagnols. Il importe en effet au prince de

(46) JeAn Molinet, Le voyage d'Espaigne, op. cit., p. 373, v. 9 et 13-14.

(47) ID., L'alliance matrimoniale, op. cit., p. 336, v. 19-20.

(48) Ibid., p. 337, v. 49-56.

(49) Ibid., p. 338 , v. 82-83.

(50) Ibid., p. 335, v. 3, 5, 8 et 13.

(51) On remarquera ici une représentation du monde physique, végétal et animal tout à fait utilitariste : celui-ci doit être domestiqué par l'homme pour le servir. L'image donnée de l'Espagne est ainsi tout à fait idyllique, ce qui tranche avec la réalité plutôt âpre et aride de certain paysage castillan.

(52) Signalons que la métaphore végétale est une constante dans l'imaginaire politique tardo-médiéval afin de représenter le royaume (Colette BEAUnE, Naissance de la nation France, Paris, Gallimard-NRF, 1985, p. 318-322). Comme dans les Pays-Bas, elle connaît des développements particuliers en France au début du XVI ${ }^{\mathrm{e}}$ siècle (Jonathan DuMONT, Lilia florent. L'imaginaire politique et social à la cour de France durant les Premières Guerres d'Italie (1494-1525), Paris, Honoré Champion, 2013, p. 60-61 et 71-72). 
connaître le mieux possible ses nouveaux sujets. Dans une lettre, datée des $1^{\text {er }}$ et 2 juin 1506, adressée par Don Diego de Guevara († 1520) ${ }^{(53)}$ à Philippe le Beau, l'auteur conseille au souverain d'utiliser de belles paroles, car celles-ci ne coûtent rien et rapportent beaucoup, surtout en Espagne, à cause que la nation est ung peu glorieuse ${ }^{(54)}$, autrement dit vaniteuse ${ }^{(55)}$. Quelques jours plus tard, le 6 juin, le même Guevara enjoint son maître à ne pas toucher à l'Inquisition car, sinon, Philippe risquerait de perdre beaulcop de bonnes volentez des nobles gens de ces royalmes ${ }^{(56)}$. Dans ses deux lettres, Guevara évoque à la fois la nécessité politique de comprendre la mentalité des Espagnols, leur tournure d'esprit - même si sous sa plume celle-ci apparaît très stéréotypée - ainsi que leurs coutumes et leurs pratiques institutionnelles. Guevara enjoint son prince à agir avec prudence et diplomatie dans une Espagne qui voyait avec méfiance, sinon hostilité, l'arrivée d'étrangers dans les sphères du pouvoir. Toutefois, dans sa lettre, il demeure peu loquace sur la question (par prudence ? par peur d'être lu par des Espagnols qui s'offusqueraient de sa remarque ?). Difficile à dire, même si l'on imagine que le conseiller réserva ses avis les plus détaillés aux oreilles de son prince, et non au papier de ses missives ${ }^{(57)}$. Philippe le Beau avait d'ailleurs parfaitement compris le message de Guevara. Il devait apprendre de ses nouveaux sujets, afin de mieux les gouverner, ainsi que le révèle Antoine de Lalaing, lorsqu'il relate comment, le 18 janvier 1503,

(53) Diego de Guevara est écuyer tranchant puis maître d'Hôtel de Philippe. Il accompagne ce dernier en Espagne lors de ses deux voyages et sera d'ailleurs l'un des agents principaux de la politique du prince en Castille. À la suite de son maître, en 1506, il quitte la péninsule pour ne pas subir les foudres de Ferdinand d'Aragon, et poursuit sa carrière au service de Charles de Habsbourg, en tant que membre du Conseil privé et grand maître de l'Ordre de Calatrava. Voir Jean-Marie CAUCHIES, " Les étrangers dans l'entourage politique de Philippe le Beau ", dans Revue du Nord, t. 84, $\mathrm{n}^{\text {os }}$ 345-346, avril-septembre 2002, p. 413-428 (ici p. 424) ; H. CoOLS, Mannen met macht, op. cit., p. 225-226 ; R. FAGEL, De Hispano-Vlaamse wereld, op. cit., p. 326-327 ; Adrían LÓPEZ ÁlvareZ, " Guevara, Diego de », dans DBE, t. 25, 2009, p. 88-89.

(54) Don Diego De Guevara, Lettre à Philippe le Beau, Villafranca, $1^{\text {er }}$ et 2 juin 1506, dans L.-Pr. GACHARD, ed., Collection des voyages, op. cit., t. 1, no 15, p. 514.

(55) Sur le sens précis de "Glorieux », en moyen français, voir Art. " Glorieux ", Dictionnaire du moyen français (1350-1500) (= DMF), en ligne, http://atilf.atilf.fr/scripts/ dmfX.exe?IDF=dmfXdXpcYgcb;ISIS=isis_dmf2012.txt;MENU=menu_dmf;OUVRIR_ MENU $=2 ; \mathrm{OO} 1=-1 ; \mathrm{s}=\mathrm{s} 13431604 ; \mathrm{LANGUE}=\mathrm{FR} ; \mathrm{FERMER} ; \mathrm{AFFICHAGE}=0 ; \mathrm{MENU}=\mathrm{me}$ nu_dmf; XMODE=STELLa;FERMER;XXX=4, consultation le 13 février 2016.

(56) Don Diego De Guevara, Lettre à Philippe le Beau, s.d. (6 juin 1506), dans L.-Pr. GaChard, ed., Collection des voyages, op. cit., t. 1, no 17, p. 519. L'Inquisition est en effet l'un des instruments du pouvoir des Rois catholiques, en particulier en Castille (Miguel Ángel LADERO QUESADA, « Isabelle de Castille : exercice du pouvoir et modèle politique ", dans Éric Bousmar, Jonathan DumOnT, Alain MARCHANDISSE \& Bertrand SCHNERB, eds, Femmes de pouvoir, femmes politiques durant les derniers siècles du Moyen Age et au cours de la première Renaissance, Bruxelles, De Boeck, 2012, p. 47-66 [ici p. 59]).

(57) L'apprivoisement mutuel et les conflits des noblesses bourguignonnes et ibériques sont décrits, sur le temps long, par René VERMEIR, «"Je t’aime, moi non plus". La nobleza flamenca y España en los siglos XVI-XVII », dans Bartolomé YUn CASAlilla, ed., Las redes del imperio. Élites sociales en la articulación de la Monarquía Hispánica, 14921714, Madrid, Marcial Pons, 2009, p. 313-337. 
Monseigneur [alla] véoir en habit incongneu les réjouissances urbaines, auxquelles s'adonnaient les Barcelonais ${ }^{(58)}$.

Mais c'est surtout de façon indirecte, sans exprimer ouvertement le souhait d'instruire leur lecteur - donc le prince - que nos auteurs deviennent source d'information sur les mœurs espagnoles. À nouveau, leur curiosité les motive.

Antoine de Lalaing rend compte des spécificités de l'Église d'Espagne, notamment ses rites lors des jeudi et vendredi saints, ou encore ses coutumes funéraires ${ }^{(59)}$. Enfin, à Saragosse, tout en se montrant critique à l'égard des musulmans, qui rendent leur abhominable sacrifice à leur Machommet, Lalaing se montre très curieux de leurs traditions religieuses qu'il observe régulièrement (journèlement les alièmes vëoir) ${ }^{(60)}$. Il prouve ainsi que les Bourguignons avaient compris, dans une certaine mesure, la complexité du contexte confessionnel espagnol dans lequel leur maître allait être appelé à s'insérer pour régner.

Laurent Vital est certainement celui de nos auteurs qui se fait le plus fin observateur des sociétés ibériques. Il s'intéresse aux habitudes vestimentaires et cosmétiques des Castillans ${ }^{(61)}$, à leurs pratiques religieuses, comme cette messe célébrée par des marins lors de la traversée de Charles vers l'Espagne ${ }^{(62)}$, ou encore à certains détails propres aux cérémonies du pouvoir ibériques (danses de cour, vaisselle d'apparat) ${ }^{(63)}$. Le chroniqueur compare

(58) Antoine De Lalaing, Voyage, op. cit., p. 256.

(59) Ibid., p. 171 (jeudi et vendredi saints), 193-194 (extrême onction), 197 (pratiques funéraires).

(60) Ibid., p. 247. Lalaing décrit fort longuement la prière du vendredi dans la mosquée de Saragosse. Tout en faisant preuve de curiosité et d'une certaine précision dans sa description, il véhicule nombre d'erreurs communes aux chrétiens du temps sur la religion musulmane (la plus répandue étant que les musulmans idolâtrent Mahomet) : Ils commenchent venir à leur melchitte environ XII heures de midi ; et avant qu'ilz entrent, se despouillent et à une fontaine illec sourdante se lavent des piedz jusques à leur tête, et dient qu'ilz se purgent par ce lavement de leurs péchiés, comme nous par confession, puis se revestent et entrent en leur melchitte la pluspart natée; et venus jusques as nattes, ostent leurs cauchiers, car il leur est deffendu en leur loy marchier dessus, fors à piedz nudz. Les homes sont d'ung costé et les femmes d'ung aultre, et ne se entrevoyent; et leur allefaquin, revestu d'une chappe de drap blan et de chaperon de mesme, come ung moisne, tenant une croche, list une grosse heure. Tous les homes, en fin de sa lecture, se escrient et lamentent, puis dient je ne sçay quèle dévotion en leur loy escripte, come avons les Heures ; et dure cela environ deux bones heures. Ce faisant, se lièvent pluseurs fois, et baisent la terre à chescune levée trois fois ; puis se rassient, et assis baisent derecief la terre pluseurs fois. Ces cérimonies faictes, l'allefaquin sermone bien une demie heure; puis boutte sa teste en ung trou où il faict quelque pryère à leur dieu Machommet; et tous les homes en font aprés luy otant. Ce acompli, reprendent leurs souliers sur les roiles atachiés as murailles entour leur melchitte; puis retournent à leurs maisons. Et font cela seulement une fois la sepmaine : c'est le venredi, lequel ils festient comme nous le dimence, et n'entrent en leur melchitte sinon ce jour. Leur prebstre puet avoir femmes et enfans, comme l'ung d'euls (ibid., p. 247-248).

(61) Laurent Vital, Premier voyage, op. cit., p. 94-95, 98-99, 148 et 155.

(62) Ibid., p. 69-70.

(63) Ibid., p. 115-120 et 252. On trouve aussi mention de la vaisselle et des danses chez Antoine DE Lalaing, Voyage, op. cit., p. 153, 165, 176, 180, 212, 249, 251, 258 et 265. Sur l'une et l'autre traditions, voir Álvaro FERnÁndeZ DE CóRdova Miralles, La corte de Isabel I. Ritos y ceremonias de una reina (1474-1504), Madrid, Dykinson, 2002, p. 248 et $271-279$. 
surtout la condition sociale des Castillans à celle des habitants des Pays-Bas, sans toutefois se prononcer systématiquement en faveur de son pays. Par exemple, s'il insiste sur les terribles conditions de travail des serviteurs en Castille par rapport aux Pays-Bas ${ }^{(64)}$, plus loin, il loue le crédit que [...] ont [en Castille] les gens d'église ${ }^{(65)}$ et estime que les marchands castillans se comportent mieux - plus humblement - que ne le font les Gantois, Brugeois et Allemands, lesquels s'emparent des biens de Dieu indiscrètement [...] de quoy Dieu est bien souvent grandement offensé(66). Dans ces deux exemples, on constate que le jugement de valeur que porte Vital est fortement marqué par une conception de la hiérarchie sociale favorable au clergé et à la noblesse, propre à la société curiale bourguignonne dont il fait partie. Le chroniqueur s'intéresse également au statut des femmes dans la société castillane. Lors d'un spectacle de danse organisé à la demande du roi, il loue la bonne volonté des danseuses castillanes qui s'exécutent sans protester, alors qu'aux PaysBas si les nostres vinssent récréer gens de bien sans estre appellées, elles ne auroyent garde, mais les fauldroit bien prier et prendre à point, et encor peutestre que rien ne feroient ${ }^{(67)}$. Il avance également qu'en Castille les dames et damoyselles y sont, de leurs maris et touttes gens de bien, fort extimées, honnorées et chières tenues. Celles-ci sont en effet toujours accompagnées en rue par leur époux ou par un homme de confiance (un chapelain), et portent, en public, des vêtements aux couleurs d'ordres religieux pour l'amour de leurs amis $^{(68)}$. Si Vital semble donc accorder sa préférence aux Castillanes, c'est avant tout parce que les codes sociaux qui encadrent leurs comportements les rendent plus dociles que ne le sont les femmes des Pays-Bas, ce qui ne semble pas lui déplaire ${ }^{(69)}$.

\section{L'espace urbain}

La ville constitue bien entendu un champ d'observation privilégié du fait politique. Il serait toutefois caricatural de dire que tous nos auteurs tirent systématiquement des enseignements de leur visite des villes espagnoles. Antoine de Lalaing s'y intéresse pour des raisons spirituelles, décrivant dans le détail les édifices religieux qui souvent motivent sa visite d'une ville ou d'un bourg. Sa foi le conduit sur le chemin de Saint-Jacques-de-Compostelle. Arrivé dans la cité sainte, il livre une description détaillée de la cathédrale, de ses reliques et de son trésor ${ }^{(70)}$. Lalaing témoigne également d'un goût pour

(64) Laurent Vital, Premier voyage, op. cit., p. 258.

(65) Ibid., p. 255.

(66) Ibid., p. 259. Il s'agit des biens ecclésiastiques.

(67) Ibid., p. 117.

(68) Ibid., p. 255-256.

(69) Lalaing consacre aussi quelques passages aux dames de Castille, mais en se contentant surtout de décrire leurs habits, comme les coevre-ciefs, [de] XX ou XXX aulnes de toilles des Basques, ou les habillemens des femmes de Grenade qu'il trouve fort estranges (ANTOINE DE LALAING, Voyage, op. cit., p. 150 et 208).

(70) Ibid., p. 158-160. Les descriptions de reliques et de trésors d'églises s'accumulent, qu'il s'agisse de cathédrales (ibid., p. 173 [Madrid] et 181-182 [Tolède]) ou d'édifices plus modestes (ibid., p. 156-157 [San Salvador] et 165-166 [Dueñas]). 
la découverte des villes que nous pourrions qualifier de « touristiques ». On le constate lors du long voyage qu'il entreprend vers Grenade, puis Valence, et notamment dans la longue description qu'il consacre au palais de l'Alhambra à Grenade ${ }^{(71)}$.

Lorsque des leçons politiques sont tirées de l'expérience urbaine, elles sont d'abord de nature stratégique. Dans le Premier voyage de Laurent Vital, le château de Tordesillas, comparable à la thour de Nostre-Dame d'Anvers en Brabant, est prisé pour le très bon champ de vision qu'il offre sur le pays alentours, jusques à Médine le Camp ${ }^{(72)}$. Le souci de décrire les villes pour leurs qualités militaires caractérise pleinement l'œuvre de $\mathrm{Vital}^{(73)}$, de même que celle d'Antoine de Lalaing. Ce dernier livre en effet des descriptions fort complètes des fortifications et places-fortes de villes importantes, comme Ségovie ou Perpignan ${ }^{(74)}$. Les deux textes peuvent, sous un certain angle, faire office de compte rendu stratégique et donc offrir des informations utiles au prince et à son personnel politique.

La vie matérielle des Espagnols est aussi abordée. Molinet estime, par exemple, dangereuse la ville de Tolède à cause des conditions sanitaires (c'est une cité fort puante, infecte et dangereuse pour gens delicatifz) et la promiscuité qui y règne (les putrefactions des charoignes [y] [...] engendrent le malvais aer ${ }^{(75)}$. D'une manière générale, l'indiciaire considère que le climat des villes castillanes est malsain et responsable de la mort de beaucoup de Bourguignons ${ }^{(76)}$. Les mêmes considérations se retrouvent chez Laurent Vital. À Valladolid, il décrit la manière dont les excréments des habitants tous les jours

(71) Ibid., p. 198-216 (205-206 pour l'Alhambra).

(72) Laurent Vital, Premier voyage, op. cit., p. 143. Médine le Camp : Medina del Campo : Espagne, com. aut. Castille-et-León, prov. de Valladolid, comarque de Tierras de Medina.

(73) Le château d'Aguilar de Campos (Espagne, comm. aut. de Castille-et-León, prov. de Valladolid, comarque de Tierra de Campos) est un bon anchien logis, selon la mode $d u$ pays, tandis qu'une autre place, près d'Anguilar, est quasy comme imprenable (ibid., p. 126), même si dedans elle estoit mal sorty d'artillerie et aultres munitions servans à une telle place (ibid., p. 127). Des jugements sans complaisance des places-fortes du pays se trouvent ailleurs, comme dans le cas de Treceño (Espagne, comm. aut. Cantabrie, prov. Cantabrie, munícipe Valdáliga ; ibid., p. 121), Cabuérniga (Espagne, comm. aut. Cantabrie, prov. Cantabrie ; ibid., p. 122) ou Ampudia (Espagne, comm. aut. de Castilleet-León, prov. de Valladolid, comarque de Tierra de Campos ; ibid., p. 131).

(74) Antoine De Lalaing, Voyage, op. cit., p. 169-170 et 263-264. Le long du camino francés, Lalaing repère des places de moindre importance comme Ponferrada (Espagne, comm. aut. de Castille-et-León, prov. de León, comarque d'El Bierzo) et Astorga (Espagne, comm. aut. de Castille-et-León, prov. de León, comarque de Tierra de Astorga), ibid., p. 161. En guise de complément sur ce sujet, chez Lalaing, mais aussi chez Molinet, on verra Jean-Marie CAUCHIES, " Châteaux et sources narratives au temps des premiers Habsbourg (1477-1506) », dans Jean-Marie CAUCHIES \& Jacqueline GUISSET, eds, Du métier des armes à la vie de cour, de la forteresse au château de séjour : familles et demeures aux XIV -XVI siècles, Turnhout, Brepols, 2005, p. 65-76.

(75) Jean Molinet, Chroniques, op. cit., p. 517.

(76) Ibid., p. 97. On trouve des réflexions similaires dans ANTOINE DE LALAING, Voyage, op. cit., p. 183, 193-197, 217, 220 (dénombrement des morts de l'Hôtel en raison du climat) et 189 (Philippe se réfugie dans un endroit frais et sain en dehors de Tolède) et Deuxième voyage, op. cit., p. 435 (réflexion générale sur la mortalité). 
se vuident et gectent par les rues ${ }^{(77)}$. Vital s'étend ensuite longuement sur les nombreux orphelins que compte la ville. En l'absence d'institutions de bienfaisance dignes de ce nom - à l'inverse des Pays-Bas - ces enfants couchent à même le sol de par les rues ${ }^{(78)}$. Tout n'est cependant pas négatif dans les villes espagnoles. Antoine de Lalaing juge par exemple admirable l'organisation de la prostitution à Valence. Le quartier des prostituées y forme une véritable ville dans la ville, encadré par un service d'ordre et des médecins. L'auteur juge très positives ces mesures car elles assurent la police en si vil lieu ${ }^{(79)}$.

Qu'ils les critiquent ou les louent, nos auteurs s'intéressent aux villes espagnoles parce que celles-ci constituent un terreau riche, ou susceptible de le devenir, d'où le souverain pourra tirer les revenus et les hommes nécessaires à la réalisation de sa politique. La perspective qui est la leur est très clairement utilitariste ainsi que le révèle leur intérêt prononcé pour les matières commerciales et économiques. Au début de son récit, par exemple, Laurent Vital critique l'impact néfaste de la guerre, en particulier de la Guerre de Cent Ans, sur les échanges commerciaux et la création de richesse ${ }^{(80)}$. La paix n'est pas uniquement, pour lui, un objectif moral à atteindre. Elle est un prérequis à la stabilité économique :

[...] les laboureux se remectoient à leurs labeurs, marchandise devenoit à avoir son cours, les vivres se donnoient à gracieux prix, les méchanicques et gens de stil recommençoient à besoingner pour gaigner leurs vies, les places gastées et desmolies se rédifioient, et estoit un plaisir de se trouver aux champs à veoir pasturer le bestial et comment chascun estoit ententif à aucquier, planter, labourer et remectre sus, par la belle justice qui régnoit et tenoit les chemins seurs pour tous les passans ${ }^{(81)}$.

Ainsi s'explique, dans l'œuvre de Vital, la multiplication des remarques sur la santé économique des villes espagnoles et de leur arrière-pays ${ }^{(82)}$. Souvent, pourtant, son jugement est négatif, comme dans le cas des Asturies,

(77) Laurent Vital, Premier voyage, op. cit., p. 257.

(78) Ibid., p. 181-182.

(79) En ce lieu sont trois ou quatre rues plaines de petites maisons où en chescune a filles bien gorgiases vestues de velour et de satin, et sont de deux à trois cens filles. Elles ont leurs maisoncelles tendues et acoustrées de bon linge. Le taux ordoné est quatre deniers de leur monnoye, lesquelz à nous valent ung gros [...], dont se prendt le $X^{e}$ denier, come des aultres choses cy-après déclarées, et ne puet-on plus demander pour la nuict. Tavernes et cabarès y sont. On ne puet, pour la chaleur, si bien véoir ce lieu, de jour, que on faict de nuict au soir : car elles sont lors assises à leurs huys, la belle lampe pendante emprès d'elles, pour les mieulx véoir à l'aise. Il y a deux médecins ordonnés et gagiés à la ville pour chescune sepmaine visiter les filles, à sçavoir se elles ont aulcunes maladies, pocques, ou aultres secrètes, pour les faire widier du lieu. S'il en y a aulcune malade de la ville, les signeurs d'icelle ont ordonet lieu pour les mettre, à leurs despens, et les foraines sont renvoyées où elles voelent aller. J'ay ce escrit pour ce que je n'ay ouy parler de mettre telle police en si vil lieu (ANTOINE DE LALAING, Voyage, op. cit., p. 214).

(80) Laurent Vital, Premier voyage, op. cit., p. 10-12.

(81) Ibid., p. 11-12.

(82) Le pays de Treceño (Espagne, com. autonom. Cantabrie, prov. Cantabrie, mun. Valdáliga.), beau, vert et fructueux, est loué pour l'abondance de son blé, de ses vins, de ses moulins et de ses salines (ibid., p. 121-122). On trouve une description semblable à propos de Valladolid (ibid., p. 142). 
pays pauvre, selon lui, parce que les habitants refusent de travailler la terre, s'estimant nobles en vertu d'anciens privilèges ${ }^{(83)}$. Dans le cas du pays de Revenga, qu'il juge pauvre et stérile, Vital insiste sur la gravité de la pénurie de bois qui frappe la région. Par sa rareté, le bois devient trop cher et les pouvres gens $n$ 'ont point d'argent pour y faire édiffier ${ }^{\left({ }^{84}\right)}$. Le problème du bois de chauffage se pose, en général, dans toute la Castille ${ }^{(85)}$. Vital propose alors des solutions. Il imagine une campagne de reboisement à grande échelle ${ }^{(86)}$, étant entendu que, pour lui, qui dit amélioration de la santé économique du pays, dit augmentation des revenus du prince et, donc, renforcement de son pouvoir ${ }^{(87)}$.

L'exercice de la justice retient également l'attention des auteurs. Celui du Deuxième voyage de Philippe le Beau estime, par exemple, que les :

[...] Galiciens sont enclins à larcin, comme ilz sont et ne s'en sauroyent tenir, et ont bien rémission de larcin aussi légièrement que ont ceulx du païs de la Leuwe rémission d'avoir abatu ung chesne, c'est-à-dire tué ung homme de beau fait $[\ldots]^{(88)}$.

(83) [...] et croy que si les gens y estoient ausy dilligens à labourer comme par dechà et cultiver les terres, qu'ilz auroient, sans comparaison, trop plus de biens qu'ilz n'ont: mais il ne leur chault de labourer, sinon seulement ce qui leur convient pour gouverner eulx et leur mesnye, car ilz sont la pluspart fondez sur gentillesse, jasoit ce qu'ilz soyent pauvres, et se disent tous estre nobles en vertu de certains previléges qu'ilz ont acquis des roys de Castille [...] (ibid., p. 94).

(84) Ibid., p. 128. La production agricole est aussi mise en question en Castille. Vital énonce cette réalité au moment de décrire un repas en l'honneur de Charles à Valladolid. Les mets sont plus à extimer, selon lui, que dans les Pays-Bas car en ce quartier-là [en Castille] on y recouvre fort mal de ce qu'il convient avoir pour festoyer gens de bien (ibid., p. 158-159). La valeur des plats est plus grande que dans les Pays-Bas, car les ingrédients qui les composent sont plus rares. L'auteur du Deuxième voyage, op. cit., p. 450, évoque lui aussi, de manière générale, la très-grande povreté qui estoit èsdicts royaulmes. Revenga : Espagne, Com. aut. de Castille-et-León, prov. de Palencia, comarque de Tierra de Campos.

(85) LaUrent Vital, Premier voyage, op. cit., p. 143.

(86) Il m'est advis que, si les habitans de celle contrée augioient et plantoient des arbres en plusieurs lieux, et principalement du long des rivières, où le pays et terre est moicte, qu'ilz auroient plus de bois qu'ilz n'ont : car, jà soit ce que la terre en plusieurs quartiers de Castille soit stérille, si esse trop plus grande chose que ne cuidoye (ibid., p. 143).

(87) Un tel souci des revenus du prince se retrouve chez Antoine de Lalaing qui signale, d'une part, les villes et les lieux remarquables d'où Philippe peut espérer tirer du numéraire (ANTOINE DE LALAING, Voyage, op. cit., p. 156 [mines du pays d'Astorga], 157158 [Burgos], 211 [pays de Valence] et 256-257 [Barcelone et son port]), et, d'autre part, les impôts qu'il pourra lever dans ses royaumes de Valence et de Castille (ibid., p. 215 et 231-237). Cette vision toute économique, et donc pragmatique, d'un nouveau territoire se retrouve chez les Français occupant l'Italie du Nord à la même époque (J. DuMONT, Lilia florent, op. cit., p. 432-436). Enfin, signalons qu'il y a plus de nuances dans le Deuxième voyage. Si l'auteur admet que la situation économique des royaumes ibériques n'est pas florissante (Deuxième voyage, op. cit., p. 450), il considère que les difficultés d'approvisionnement de l'Hôtel royal sont dues à une mauvaise intendance (ibid., p. 436). On pourrait également y voir là un règlement de compte entre le chroniqueur, et le trésorier général Jérôme Lauwerin et son personnel (Jean-Marie CAUCHIES, « Voyage d'Espagne et domaine princier : les opérations financières de Philippe le Beau dans les Pays-Bas (1505-1506) », dans Philippe Contamine, Thierry Dutour \& Bertrand SchnerB, eds, Commerce, Finances et Société (XIe-XVI e siècles). Recueil de travaux d'Histoire médiévale offert à M. le Professeur Henri Dubois, Paris, PUPS, 1993, p. 217-244).

(88) Deuxième voyage, op. cit., p. 437. 
Le problème de la criminalité est comparé par le chroniqueur à la situation du païs de la Leuwe dans les Pays-Bas ${ }^{(89)}$. L'anonyme dénonce la manière dont la justice est exercée dans les deux pays. L'exercice de la « bonne » justice est nécessaire à l'entretien de la police - de l'ordre - dans le royaume ${ }^{(90)}$. À ce propos, Espagne et Pays-Bas auraient beaucoup à apprendre les uns des autres de l'autre selon Laurent Vital. Lorsqu'il évoque la ville de Valladolid, tout plain de larchins et aultres maulvais actes, il condamne la manière dont les vols sont traités :

[...] plusieurs larchins se commectent parce que, à la IIIIe ou ve fois, ne sont pugnis selon leurs démérites et persévèrent sans crainte, extimant que, se ilz sont prins, eschaperont, comme aultre fois ont faict, par estre fustiguiés sur l'asne.

C'est-à-dire qu'en Castille les voleurs, récidivistes ou non, sont condamnés à être promenés sur un âne de par les rues et à être montrés à la population. Mais, pour Vital, ceulx qui sont coustumiers de desrobber, pour telle fustigation ne se corrigeront poinct après avoir subi ce châtiment. Il faudrait que la rigueur de la sentence aille croissant en fonction de la récidive. Dans les Pays-Bas, les récidivistes ont les oreilles coupées, voire, dans les cas les plus graves, sont mis à mort, tout ceci afin qu'ilz prengnent une crainte et vergongne et se abstiennent de tant plus tost ${ }^{(91)}$. Ici, les Espagnes doivent prendre exemple sur les Pays-Bas. Dans d'autres cas, par exemple celui de la lutte contre la corruption, c'est le contraire. En Castille, la corruption des magistrats est réfrénée car il leur est espressément deffendu de, en leur office faisant, ne rechepvoir argent ne aultre don, pour advanchier ou délayer de faire justice $[\ldots]$ sur peine d'estre criminellement pugny. Qui plus est, les gens de justice reçoivent bon gaiges et pensions [...] pour en vivre honnestement ${ }^{(92)}$. Vital estime grandement de telles dispositions anti-corruption, sources d'inspiration pour les Pays-Bas (?) ${ }^{(93)}$.

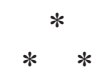

(89) S'agit-il de la région de Lauwe (Belgique, rég. flamande, com. flamande, prov. Flandre-Occidentale, arr. Courtrai, com. Menin) ? Rien n'est certain.

(90) A. Rigaudière définit le concept d'ordre/police comme une manière de « désigner les tâches administratives les plus variées, la capacité d'édicter des normes en vue d'en réglementer la gestion ou, encore, les organes investis du pouvoir de les mener à bien » (Albert Rigaudière, "Les ordonnances de police en France à la fin du Moyen Âge ", dans ID., Penser et construire l'État dans la France du Moyen Âge (XIII -XV siècle), Paris, Comité pour l'Histoire économique et financière de la France, 2003, p. 285-341 [ici p. 285]). L'expression est liée autant à la justice, au gouvernement qu'à l'ordre au sens philosophique. L'ordre/police désigne donc une manière organisée et ordonnée de gouverner, et renvoie ainsi à une manière d'agir conformément aux lois.

(91) Laurent Vital, Premier voyage, op. cit., p. 182-183.

(92) Ibid., p. 253.

(93) Antoine De Lalaing, Voyage, op. cit., p. 189, évoque lui aussi, bien que brièvement, le système judiciaire castillan par le biais de l'anecdote d'un voleur, ce qui l'amène à parler des exécutions capitales dans le pays, mais sans se positionner. 
La découverte de l'Espagne par nos auteurs suscite nombre d'observations qui sont susceptibles d'avoir des implications politiques. Des trois matières qui retiennent en priorité leur attention (nature, mœurs, villes) émergent parfois des leçons politiques. La métaphore végétale, chez Jean Molinet, permet d'exalter les futures possessions espagnoles de Philippe le Beau. Les comportements des Castillans doivent, pour Diego de Guevara, être compris et utilisés par le souverain pour mieux gouverner. Quant aux descriptions de l'espace urbain, elles sont, aux yeux d'un Vital, d'un Molinet ou d'un Lalaing, sources d'enseignements stratégiques, économiques, fiscaux et juridiques. En l'informant, en le conseillant, tous ces auteurs aident leur prince à renforcer son pouvoir en Espagne.

\section{Esprit de famille}

Cependant, si des informations fiables et de bons conseils peuvent inspirer un gouvernement, ils n'établissent pas le droit du prince à régner, sa légitimité au trône. Celle-ci repose essentiellement sur les liens familiaux qui existent entre Philippe et Charles, d'une part, et les Rois catholiques, d'autre part. Le début du $\mathrm{XVI}^{\mathrm{e}}$ siècle voit en effet se jouer une véritable bataille politique, symbolique et littéraire visant à légitimer les princes austro-bourguignons en tant qu'héritiers, puis souverains des royaumes espagnols ${ }^{(94)}$.

Il serait faux de penser que nos deux princes sont accueillis à bras ouverts en Espagne. C'est en fait tout le contraire. En 1506, Philippe fait face à son beau-père Ferdinand d'Aragon, soutenu par une part importante de la noblesse. Celle-ci espère voir l'Aragonais régir la Castille au nom de sa fille Jeanne, en lieu et place de Philippe, un prince étranger qui ne leur apparaît pas légitime ${ }^{(95)}$. Durant le premier voyage de Charles, la mainmise qu'il entend établir sur

(94) Remarquons que cette lutte pour la dignité royale commence bien avant l'arrivée de Philippe en Espagne. On sait, par exemple, à quel point l'entrevue entre Louis XII et Philippe le Beau, en 1501, à Blois, fut le théâtre d'une bataille de préséances acharnée entre Jeanne de Castille et Anne de Bretagne. Certes, à cette époque, Philippe n'était qu'un roi en devenir, un prince héritier, mais déjà son épouse entendait bien démontrer à tous, surtout aux Français, qu'il était quasi égal au roi de France et qu'elle, en tant qu'héritière de Castille, n'avait pas à céder le pas devant la reine (voir Monique CHATENET $\&$ Pierre-Gilles GIRAULT, Fastes de cour. Les enjeux d'un voyage princier à Blois en 1501, Rennes, P.U. de Rennes, 2010, p. 40-46).

(95) Les opposants aux Bourguignons utilisent les Cortès de Castille et la reine Jeanne pour affaiblir la position de Philippe. La situation ne se stabilise qu'à la suite d'une rencontre entre Philippe et Ferdinand à Remesal (20 juin 1506), prélude à un accord signé les 27 et 28 juin entre les deux hommes (Bethany ARAM, Juana the Mad. Sovereignty and Dynasty in Renaissance Europe, Baltimore-Londres, The Johns Hopkins University Press, 2005, p. 75-83 ; ID., " Voyages from Burgundy to Castille », op. cit., p. 102-107 ; J.-M. CAUCHIES, Philippe le Beau, op. cit., p. 189-195 et 199 ; J. PÉrEZ, Isabelle et Ferdinand, op. cit., p. 381-385). L'auteur du Deuxième voyage, op. cit., p. 254, rend compte de ces tensions après la mort de Philippe. Les tensions sont aussi suscitées par la compétition culturelle et politique qui naît entre les Bourguignons et les Espagnoles (B. ARAM, « Voyages from Burgundy to Castille », op. cit., p. 98). Plus généralement, sur les relations aigres-douces entre Ferdinand et Philippe, voir Joseph PÉREZ, "Fernando el Católico y Felipe I el Hermoso ", dans Benjamín GonzÁlez Alonso, ed., Las Cortes y las leyes de Toro de 1505. Actas del congreso conmemorativo del $v$ Centenario de la celebración de 
l'Espagne, notamment en prenant le contrôle des offices et bénéfices pour les redistribuer à des Bourguignons fidèles, suscite l'ire d'une part importante de la noblesse et du clergé. À ces tensions, prémices de la révolte des Comuneros (1520-1521), il faut ajouter la mésentente croissante entre Charles et sa mère, laquelle entend conserver un pouvoir effectif dans son royaume, alors que son fils n'est pas prêt à le lui accorder ${ }^{(96)}$.

Pour toutes ces raisons, on comprend mieux pourquoi nos auteurs insistent à ce point sur les liens dynastiques qui unissent les Pays-Bas aux Espagnes. Ils le font principalement à trois moments : dans les récits des rencontres entre les princes austro-bourguignons et leurs parents espagnols ; au moment d'évoquer, dans ce qui s'apparente à de courtes biographies, la vie des Rois catholiques; lors des cérémonies funèbres organisées à Bruxelles après les décès d'Isabelle et de Ferdinand.

\section{Rencontres princières}

Les rencontres entre Philippe le Beau et les Rois catholiques constituent des moments privilégiés favorisant la construction d'une image royale. Elles le font en effet apparaitre comme un quasi rex.

Lors de son premier séjour dans la péninsule Ibérique, Philippe le Beau tomba malade et fut contraint de séjourner quelque temps, près de Tolède, dans le village d'Olías del Rey (30 avril-7 mai 1502) ${ }^{(97)}$. Ferdinand d'Aragon vint à son chevet. Jeanne de Castille accueillit son père, l'embracha et baisa [sa main], puis le conduisit dans la chambre où Philippe se reposait. Là, Ferdinand osta incontinent son bonnet, s'approcha du prince, lequel bougier ne pooit, mais osta son bonnet, et print la main du roy et le baisa à force, bien que Ferdinand ne le voloit souffrir. Tous deux discutèrent un certain temps, Jeanne jouant les interprètes ${ }^{(98)}$. Témoin de l'événement, Antoine de Lalaing s'emploie à démontrer qu'une sorte de familiarité et de proximité hiérarchique existe entre les deux princes. Ferdinand refuse que Philippe s'acquitte du

las Cortes y de la publicación de las Leyes de Toro de 1505, Toro, 7 a 19 de marzo de 2005, Madrid, Cortes Castilla y León, 2006, p. 159-174.

(96) Laurent Vital, Premier voyage, op. cit., p. 18, 137-139, 238 et 246-248, relate ces événements. Sur ceci, on verra Joseph PÉREZ, « Moines frondeurs et sermons subversifs en Castille pendant le premier séjour de Charles-Quint en Espagne ", dans Bulletin hispanique, t. 67, $\mathrm{n}^{\mathrm{os}} 1-2,1965$, p. 5-24 ; B. ARAM, Juana the Mad, op. cit., p. 117 ; P. Chaunu \& M. Escamilla, Charles Quint, op. cit., p. 110-116, 141-154 et 172-189; K. BRANDI, Charles Quint, op. cit., p. 76-77, 79-91 et 140-146 ; R. FAGEL, De HispanoVlaamse wereld, op. cit., p. 342-343. Il apparaît également que Charles a voulu, dès 1517, remanier sa cour sur un modèle bourguignon, ce qui lui aliéna une partie de la noblesse castillane et aragonaise (José MARTínez Millán, "The Triumph of the Burgundian Household in the Monarchy of Spain. From Philip the Handsome (1502) to Ferdinand VI (1759) », dans W. PARAVICINI, T. HiLTMAnN \& Fr. ViltaRT, eds, La cour de Bourgogne, op. cit., p. 745-771 [ici p. 748-749]).

(97) Olías del Rey : Espagne, com. aut. Castille-La Manche, prov. de Tolède, comarque La Sagra.

(98) Antoine de Lalaing, Voyage, op. cit., p. 173 ; voir aussi J.-M. Cauchies, Philippe le Beau, op. cit., p. 138. 
baisemain dont tous les nobles espagnols l'honorent habituellement ${ }^{(99)}$. Le roi se découvre même devant le malade. Évoquant lui aussi l'événement, Molinet renforce cette proximité. Pour lui, le roy approcha et monseigneur fit signe de soy lever, [...] le roy ne le souffri, ains se hasta sy le vint embracier, et monseigneur se mit en paine de baisier la main du roy et le roy le mucha [cacha]. Le rapprochement symbolique entre les deux hommes est encore plus grand puisque Ferdinand refuse que Philippe se lève, scène absente chez Lalaing. Molinet achève son récit en insistant sur le grant amour qui règne entre les deux princes ${ }^{(100)}$. Chez Lalaing et Molinet, la distance symbolique qui devrait exister entre Ferdinand et Philippe, reflet d'une différence de statut - l'un est roi, l'autre non -, est atténuée - fortement dans le texte de Molinet. Les deux chroniqueurs préfèrent placer la rencontre sur le plan de l'affectif et des rapports familiaux. Cette tendance se manifeste d'ailleurs à d'autres moments au cours du premier voyage de Philippe. Lors de l'entrée de l'archiduc à Tolède, le 7 mai 1502, Ferdinand empêche à deux reprises Philippe de mettre pied à terre avant de lui donner l'accolade. Philippe tente ensuite de baiser la main de son beau-père. Celui-ci refuse, mais le prince l'embrasse finalement à la dérobée. Sous un dais d'or, Ferdinand entre alors dans la cité, le couple archiducal chevauchant à ses côtés - et non derrière lui -, tel le père au milieu de ses.II. enfans ${ }^{(101)}$. Ici encore, on perçoit que les gestes des princes,

(99) Cette pratique impressionne particulièrement les Bourguignons, qui ne connaissent pas chez eux une telle mise à distance entre le prince et sa noblesse (voir quelques exemples chez Antoine de Lalaing, Voyage, op. cit., p. 515 ; JeAn Molinet, Chroniques, op. cit., p. 514 ; LAURent Vital, Premier voyage, op. cit., p. 96). Sur cet usage à la cour de Castille, on verra A.F. de CóRdova MirAlLES, La corte, op. cit., p. 231-232; Teofilo F. RUIZ, "Une royauté sans sacre : la monarchie castillane du bas Moyen Âge », dans Annales. Économies, Sociétés, Civilisations, $39^{\mathrm{e}}$ année, no 3, 1984, p. 429-453 [ici p. 442]).

(100) Jean Molinet, Chroniques, op. cit., p. 513-514. L'évènement est aussi rapporté par Philippe le BeAU, Lettre au gouverneur de Béthune, Malines, 30 mai 1502, dans L.-Pr Gachard, ed., Collection des voyages, op. cit., t. 1, no 4, p. 378. L'idée d'amour se retrouve, en 1506, dans le Deuxième voyage, op. cit., p. 390, au moment où Philippe se rend en Espagne pour entretenir [son beau-père, sa noblesse et son peuple] en son obéissance et amour.

(101) JeAn Molinet, Chroniques, op. cit., p. 514-515 (voir aussi AnTOINE DE Lalaing, Voyage, op. cit., p. 174-176 ; J.-M. CAUChies, Philippe le Beau, p. 138-139). Molinet rapporte que Ferdinand chevauche seul sous le dais (JEAn Molinet, Chroniques, op. cit., p. 515). Par ailleurs, gardons-nous de penser qu'une égalité symbolique totale est établie entre le couple archiducal et les Rois catholiques. La manière dont la cérémonie du baisemain se déroule - le roi refuse, son beau-fils l'embrasse à son insu - tient bien entendu d'une mise en scène précise qui vise à ménager à la fois la dignité, voire la susceptibilité, de Philippe et de son beau-père. Le même processus se répète quelques instants plus tard lorsque le couple archiducal rencontre Isabelle la Catholique (Ibid. ; la scène est aussi chez Antoine DE LALAing, Voyage, op. cit., p. 176). Molinet parle également d'honneurs, reverences et mistères (JEAN MOLINET, Chroniques, op. cit., p. 515 ; notion que l'on retrouve aussi chez LAUREnt Vital, Premier voyage, op. cit., p. 226) concernant ces cérémonies, ce qui place clairement les événements dans le champ du symbolique, voire du sacré (" Mystère », dans $D M F$, en ligne, http://atilf.atilf.fr/scripts/dmfX.exe?LEM=my st $\%$ E8re;XMODE=STELLa;FERMER;;AFFICHAGE $=0$;MENU=menu_dmf;;ISIS=isis _ dmf2012.txt;OUVRIR_MENU $=2 ; \mathrm{OO}=-1 ; \mathrm{s}=\mathrm{s} 13431604 ; \mathrm{LANGUE}=\mathrm{FR}$, consultation le 13 février 2016). Des éléments semblables, arguant de la parfaite entente, par exemple, entre Philippe et Ferdinand d'Aragon, se trouvent dans les textes en vers écrits bien après les événements tels NiCAISE LADAM, Histoire, op. cit., fol. 66v ; ID., Mémoire et épitaphe, 
parfaitement réglés - particulièrement le refus du baisemain, finalement accordé à la dérobée -, sont replacés par les auteurs dans le cadre de rapports familiaux et sentimentaux, ce qui leur permet d'éclipser partiellement l'aspect cérémoniel de l'événement ${ }^{(102)}$.

Le Premier voyage de Laurent Vital comporte deux scènes similaires. Le 27 novembre 1517, à Valladolid, Charles rencontre Germaine de Foix ( ca 14881536), seconde épouse de son grand-père Ferdinand et reine d'Aragon ${ }^{(103)}$. Ici, les rôles sont inversés : c'est le Bourguignon, devenu roi, qui empêche la reineveuve de descendre de cheval et de lui accorder le baisemain ${ }^{(104)}$. Un peu plus tard, au moment de son couronnement à Valladolid (7 février 1518), ses frère et sœur, Ferdinand et Éléonore, se présentent devant lui à genoux pour jurer fidélité. Charles refuse qu'ils lui baisent la main et embrasse même sa sœur par ung singne de gracieulx remerchiment. Dans les deux épisodes, la distance symbolique entre les acteurs est diminuée (non-obligation de descendre de son cheval et de baiser la main du souverain, baiser accordé par le roi à Éléonore $)^{(105)}$. Le Habsbourg est désormais passé de l'autre côté du miroir. Il tient, dans le Premier voyage, le rôle qui était celui de ses grands-parents, les Rois catholiques, chez Lalaing et Molinet, distribuant comme eux, selon une étiquette réglée, les marques de proximité symbolique. Cependant, alors que dans le cas de Philippe le Beau, le processus permettait de rapprocher le prince de ses beaux-parents, et donc de la fonction royale, dans le cas de Charles - désormais roi -, il constitue surtout un outil marquant la distance entre lui et ses proches.

\section{L'exemple des Rois catholiques}

Ce processus d'élévation de Philippe et Charles à la dignité royale se poursuit au sein d'évocations biographiques en rapport avec Isabelle de Castille et Ferdinand d'Aragon ${ }^{(106)}$.

op. cit., p. 117, v. 804-807 ; JEAN MOLINET, XXXVII. Le voyage d'Espaigne, op. cit., p. 375, v. 65-72. Enfin, remarquons que l'idée d'un Philippe « fils » de Ferdinand se retrouve chez Ladam également : Ung roy n'est poinct deceupt quand il a bons enffans (NICAISE LADAM, Histoire, op. cit., fol. 66v ; voir aussi B. ARAM, Juana the Mad, op. cit., p. 91-110).

(102) Le Deuxième voyage, op . cit., p. 390, 411-413, 437 et 450, propose une vision bien différente de ces rapports, en fait plus proche de la réalité, en montrant toute la défiance qui existe entre les deux hommes.

(103) Voir Jaime DE SAlaZAR Y ACHA, Art. " Germana de Foix », dans DBE, t. 22, 2009, p. 719-722 ; José Maria Doussinague, Fernando el Católico y Germana de Foix, Madrid, Espasa Calpe, 1944.

(104) Laurent Vital, Premier voyage, op. cit., p. 159. Sur les rapports entre Charles et les membres de sa famille, on lira P. CHAUnU \& M. Escamilla, Charles Quint, op. cit., p. 113-115 ; K. BRANDI, Charles Quint, op. cit., p. 77.

(105) Laurent Vital, Premier voyage, op. cit., p. 225. Une mise en scène fort similaire a lieu lorsque Ferdinand quitte l'Espagne pour les Pays-Bas à la demande de Charles (20 avril 1518); ibid., p. 269-271.

(106) Précisons que les Rois catholiques ne sont pas les seuls ancêtres espagnols de Philippe et Charles à recevoir des éloges. Visitant les églises de Léon, Antoine de Lalaing y admire les tombeaux d'anciens rois et reines de Castille et Léon, tout en prenant soin de présenter les monarques les plus illustres, ceux qui font le plus honneur à Philippe le Beau (Antoine De Lalaing, Voyage, op. cit., p. 156). 
Ces textes et parties de textes, car il s'agit le plus souvent d'un ou deux chapitres, célèbrent avant toute chose le mariage des deux souverains (14 octobre 1469) comme l'événement majeur qui mit fin à l'anarchie en Castille. Les Rois catholiques purent alors conjuguer leurs efforts pour dompter la haute noblesse et consacrer l'union de leurs royaumes :

[...] ils espousèrent l'ung l'autre, et puis tost après réduisèrent tous les débas et dissentions qui lors estoient en ce royame, et réeult ce que à elle apertenoit, et remist tous les grands maistres subjects et obéyssans à euls plus que jamais ne avoient esté devant ${ }^{(107)}$.

Antoine de Lalaing est certainement celui qui s'étend le plus longuement sur la remise en ordre de la Castille par Isabelle. Il loue les lois qu'elle édicte afin d'empêcher les nobles de dilapider les richesses du royaume ${ }^{(108)}$, ainsi qu'un autre texte les obligeant à monter des chevaux, et ce adfin d'estre mieulx induis à la guerre ${ }^{(109)}$. Lalaing l'encense de surcroît pour avoir faict cherchier plus avant de nouvelles terres et isles ès Indes, ce qu'il considère comme une entreprise de christianisation, voire de civilisation au sens où l'on pourra l'entendre dans une phase ultérieure de la colonisation. En effet, làbas, les hommes auraient vécu tout nud et [...] brutalement come bestes, et ne sçavoient la manière de cultiver et augmenter le pays. La reine, épaulée par son époux, envoya ses navires, gens et vitailles, pour faire maisons et églises et multiplyer ces isles ${ }^{(110)}$. Elle favorisa donc la religion chrétienne tout en développant des pays restés sauvages ${ }^{(111)}$. La défense et la propagation $\mathrm{du}$ catholicisme constituent certainement les éléments les plus unanimement reconnus en faveur des Rois catholiques. À ce titre, deux éléments sont plus spécifiquement épinglés : la lutte puis la conquête du royaume musulman de Grenade (2 janvier 1492) ${ }^{(112)}$, ainsi que l'expulsion et/ou la conversion des

(107) Ibid., p. 221. Voir aussi JeAn Molinet, Epytaphe de dame Ysabeau, op. cit., p. 402, v. 33-40 ; NiCAISE LADAM, Mémoire, op. cit., p. 104, v. 429-436 et p. 116, v. 772-775. L'historiographie bourguignonne pointait déjà les éléments qui, aujourd'hui encore, sont considérés comme les conséquences majeures de ce mariage (M.A. LADERO QUESADA, « Isabelle de Castille », op. cit., p. 55-58 ; J. PÉREZ, Isabelle et Ferdinand, op. cit., p. 75-117).

(108) Antoine de Lalaing, Voyage, op. cit., p. 222.

(109) Ibid., p. 223.

(110) Ibid., p. 226. Il n'est toutefois pas certain que Lalaing fasse référence aux Amériques. Au début du passage, il parle clairement des îles Canaries (isle de Canare), qui étaient déjà une terre de peuplement pour la Castille depuis 1402. Ensuite, il évoque de nouvelles terres plus avant, ce qui pourrait faire référence à Cuba, Haïti, ou d'autres îles des Antilles découvertes par Colomb entre 1492 et 1504 (ibid., p. 226-228 ; M.A. LADERO QUESADA, "Isabelle de Castille », op. cit., p. 59-60 ; J. PÉREZ, Isabelle et Ferdinand, op. cit., p. 269-270 et 283-284).

(111) Le même constat peut être fait à la lecture du texte de Ladam. Celui-ci imagine que Ferdinand partit à la conquête des terres dans l'océan atlantique pour lutter plus efficacement contre les Turcs : Gallées et batteaulx fist passer oultre mer / Pour trouver adventure et les Turcqz escumer, / Tellement que, par fort bien waucrer et rimer, / Les Indes conquesta, qui se doit extimer (NICAISE LADAM, Mémoire, op. cit., p. 117, v. 792-795).

(112) JEAn MOLInEt, Le voyage d'Espaigne, op. cit., p. 376, v. 81-88 ; ID., Epytaphe de dame Ysabeau, op. cit., p. 404, v. 81-96 ; NICAISE LADAM, Mémoire, op. cit., p. 96, v. 213-220 ; p. 98-99, v. 281-288 et p. 110, v. 607-611. Sur les événements et le contexte intellectuel de la guerre de Grenade (aspirations millénaristes et justifications de la guerre 
juifs et des musulmans (mudéjars) ${ }^{(113)}$ qui s'ensuivit. Cette politique aurait d'ailleurs été, selon Antoine de Lalaing, inspirée à la souveraine par Philippe le Beau lui-même lors d'une entrevue ${ }^{(114)}$. Bien entendu, il est très clair que la politique coloniale et évangélisatrice de l'Espagne en Amérique ne doit rien à Philippe le Beau. En associant son prince à une telle entreprise, Lalaing récupère en quelque sorte au profit de Philippe une part de l'aura des Rois catholiques, et confère au Habsbourg l'image de champion de la chrétienté, celui qui s'apprêterait à poursuivre une telle politique.

Mais, on s'en doute, si chez nos auteurs les Rois catholiques sont estimables c'est aussi parce que, à leurs yeux, ils ont préparé les règnes de Philippe le Beau et Charles de Habsbourg. Pour Nicaise Ladam, si Ferdinand d'Aragon est un bon souverain, c'est parce que, en tant que père de Jeanne de Castille, il est l'un des maillons essentiels d'une chaîne successorale conduisant Charles à la royauté( ${ }^{(115)}$. Ferdinand aurait, qui plus est, tout fait pour assurer la paix sur ses propres terres et ainsi transmettre à son petit-fils Charles son titre royal dans la plus grande légalité. L'auteur insiste en effet sur le caractère juridiquement inattaquable de la succession :
Et tant a fait en foy fidelement
Qu'il a preveu en son antiquité
D'avoir à tous la paix unicquement,
Voeullant finer par voië d'equité
Et legater à la réalité,
Sans frauduler, title qui fut entier,
Esperant faire à bonne utilité
Droict à son filz Charles, son heritier ${ }^{(116)}$.

menée par les Rois catholiques), nous renvoyons à M.A. LADERO QUESADA, « Isabelle de Castille », op. cit., p. 58-60 et 63-65 ; J. PÉREZ, Isabelle et Ferdinand, op. cit., p. 243-260 ; Isabelle POUTRIN, Convertir les musulmans. Espagne, 1491-1609, Paris, PUF, 2012, p. 11-22.

(113) Jean Molinet, Chroniques, op. cit., p. 542-543 ; ID., Epytaphe de dame Ysabeau, op. cit., p. 403, v. 57-72 ; LAURENT Vital, Premier voyage, op. cit., p. 2-3 ; NiCAISE LADAM, Mémoire, op. cit., p. 117, v. 788-791. Les conversions forcées de musulmans et de juifs en Espagne par les Rois catholiques, épaulés par Hernando de Talavera (1428-1507), archevêque de Grenade et confesseur de la reine, et le cardinal Cisneros sont décrites dans J. PÉREZ, Isabelle et Ferdinand, op. cit., p. 213-220, 260-267 et 354-372 ; I. POUTRIN, Convertir, op. cit., p. 22-48.

(114) En ce tampz mil $v^{c}$ et ung, en may, Monseigneur, estant à Toulette avoecq le roy et la royne, fu adverti de la multitude des blans Mores habitans ès Espaignes. Esbahy du cas, enquist pourquoy on le souffroit, et on luy respondit que les grands deniers des tribus qu'ilz payoient estoit la cause : car chescune teste grande et petite payoit par an ung ducat d'or. Et Monsigneur respondit que quelque jour ils pourroient faire plus de domage au royame que leur tribut ne vault, comme ils ont aultrefois faict et cuidiet faire encoire plus. Tant continua Monsigneur ses paroles qu'elles entrèrent ens oreilles de la royne. Par quoy, pour complaire à Monsigneur, cognoissant aussy qu'il disoit chose vraye, comanda que, dedens quatre mois ou chincq ensiévans, widassent de ses pays ou se feissent baptisier et tenir nostre foy : ce que pluseurs firent, plustost, ce tien-ge, aulcuns pour garder leurs biens que pour l'amour de Dieu. Les aultres retournèrent en leurs pays : dont les pluseurs furent destroussés et pilliés aux passages (ANTOINE DE LALAING, Voyage, op. cit., p. 225).

(115) NicAise LADAM, Mémoire, op. cit., p. 96, v. 205-212.

(116) Ibid., p. 104, v. 437-444. Ladam parle ici de Charles comme du fils de Ferdinand. Il faut comprendre ce mot dans son sens juridique, Charles est le fils de Ferdinand car il est son héritier légitime, ainsi que le souligne Cl. Thiry (ibid., p. 141). 
Laurent Vital célèbre, quant à lui, Ferdinand et Isabelle pour le titre de Rois catholiques que le pape leur octroya (1494). L'événement a placé leurs Couronnes bien au-dessus de celles de leurs homologues européens. Leurs successeurs doivent nécessairement suivre leurs traces : les roys de Castille, présens et advenir, seroient dicts et nommés, par-dessus tous les roys de la chrestienneté, roys catholicques, affin de donner cour aux successeurs d'ensuyvre les vertueuses et œuvres chevalereuses de leurs prédécesseurs ${ }^{(117)}$. Aux yeux de Vital, le titre est désormais un héritage dynastique dont Charles peut s'enorgueillir, puisqu'il fait de lui le premier des rois chrétiens, et le place comme rival sérieux de cet autre premier roi des chrétiens qu'est le roi très chrétien de France ${ }^{(118)}$.

Dans ces quelques éléments biographiques, l'image royale de Philippe et de Charles se construit à partir de celle de leurs ancêtres espagnols. Les actes des deux Bourguignons sont situés dans le prolongement de ceux d'Isabelle et Ferdinand tout en les dépassant. De la sorte, ils sont parfaitement insérés dans l'histoire des royaumes ibériques en tant que continuateurs de la politique des Rois catholiques.

\section{Les obsèques des Rois catholiques}

Les liens entre les princes de la maison de Bourgogne-Habsbourg et les Rois catholiques sont également renforcés par le récit des cérémonies funèbres organisées à Bruxelles aux décès d'Isabelle et de Ferdinand.

Isabelle de Castille meurt à Valladolid le 26 novembre 1504. En marge de ses obsèques espagnoles, une cérémonie est organisée à Saint-Michel-etGudule, les 14 et 15 janvier 1505, en présence de Philippe le Beau et de Jeanne de Castille ${ }^{(119)}$. Le cérémonial tend à souligner l'accession directe de Philippe

(117) Laurent Vital, Premier voyage, op. cit., p. 3. En Espagne, l'exaltation de la figure de Ferdinand fournit des armes à ceux qui s'opposent à l'arrivée des Bourguignons en Espagne, principalement après la mort de Philippe le Beau et avant l'avènement de Charles (B. ARAM, Juana the Mad, op. cit., p. 91-110).

(118) Cette compétition entre les deux monarchies s'incarnera dans la rivalité bien connue entre Charles Quint et François $\mathrm{I}^{\mathrm{er}}$, qui connaîtra son premier pic paroxystique pendant et après les événements conduisant à la bataille de Pavie (24 février 1525). Sur celle-ci, voir le récent livre de Jean-Marie LE GALL, L'honneur perdu de François I ${ }^{e r}$, Pavie, 1525, Paris, Payot, 2015. Notons également que cette figure de parangon de la chrétienté incarnée par Philippe et Charles possède des racines toutes bourguignonnes, que le premier n'hésite d'ailleurs pas à cultiver dans les Pays-Bas, ainsi que l'a démontré Mario DAMEN, « Memoria y propaganda. Las vidrieras de Felipe el Hermoso en los Países Bajos ", dans Paul VAndenBroeck \& Miguel Angel Zalama RodrígueZ, eds, Felipe I el Hermoso. La belleza y la locura, Madrid, Centro de Estudios Europa Hispánica, 2006, p. 165-184.

(119) Jean Molinet, Chroniques, op. cit., p. 538-541 : [Chapitre CCCIX.] Des obsèques celebréz en Bruxelles pour très catholique princesse, madame Ysabel, royne de Castille, de Leon et Grenate. Le récit de ces cérémonies est aussi présent, mais de manière plus concise et moins élaborée, dans L'obsèque de feu madame Isabel, en son temps royne de Castille, de Leon, de Grenade, etc., faict en la ville de Bruxelles par monseigneur l'archiduc, prince de Castille, etc., le mardy XIIII et mercredy XV jour du mois de janvier l'an mil $V^{e} V$, éd. Relation des obsèques célébrées à Bruxelles, les 14 et 15 janvier 1506 
au trône de Castille. Toute une symbolique royale est ainsi déployée. Dans le cortège, on découvre une couronne royale :

Dessus la selle dudit palefroy, estoit ung quarré de veloux, sur ycellui une coronne royale d'or fort rice, et adextroient ladite coronne le duc de Clèves et le prince de Chimay ${ }^{(120)}$.

Dans l'église, la même couronne est ensuite posée sur la bière, évocation de la reine défunte et du pouvoir qu'elle incarnait. Cette puissance monarchique est également représentée grâce aux armes des trois principaux royaumes sur lesquels régnait Isabelle, et qui constituent le nouveau domaine de Philippe et Jeanne, c'est-à-dire Castille, Léon et Grenade ${ }^{(121)}$. Enfin, le point d'orgue de la cérémonie est atteint lorsque le héraut Toison d'or proclame, devant l'effigie de la reine, "Très haulte, très excellente, très puissante et très catholique " et qu'on lui répond : "Elle est morte, de très vertueuse et loable mémoire ". Toison d'or clame alors par trois fois : "Vive dom Philippe et donne Joanne, par la grace de Dieu roy et royne de Castille, de Leon et de Grenate ", et dépose au pied de l'autel sa verge symbole de ses fonctions, suivi par les officiers royaux ${ }^{(122)}$.

La cérémonie bruxelloise fournit ainsi l'occasion d'entourer Philippe le Beau de nombreux symboles monarchiques, mais aussi d'associer - peutêtre pour la première fois ? - une symbolique bourguignonne à une autre castillane $^{(123)}$. L'événement est conçu pour signifier qu'une transmission immédiate du pouvoir a lieu entre Isabelle et Philippe.

(n. st.), pour la reine Isabelle la Catholique, dans Louis-Prosper GACHARD, Analectes historiques, t. 3, Bruxelles, Académie royale de Belgique, 1863, p. 297-302. Notons que le point de vue de l'auteur anonyme du Deuxième voyage est totalement différent, malgré la brièveté de son récit (Deuxième voyage, op. cit., p. 389). À propos de la cérémonie de Bruxelles et son contexte immédiat, voir J.-M. CAUCHIES, Philippe le Beau, op. cit., p. 164.

(120) JeAn MOLinet, Chroniques, op. cit., p. 540.

(121) Ibid., p. 539. On pourrait également déceler dans cette cérémonie une symbolique des nombres, principalement du nombre trois (les trois royaumes d'Isabelle). Molinet insiste en effet sur trois porteurs de flambeaux, sur les trois évêques présents (Il y avoit .III . hommes revestus et enchaperonnéz du doeul [...]; [... .III. evesques, c'est assavoir, le suffragant d'Utrecht, l'evesque de Tournay et l'evesque d'Arras [...]. ibid.). Toutefois, la régularité de cette symbolique ternaire n'est pas parfaite, car à un autre endroit ce ne sont pas trois mais quatre royaumes (la Galice fait son apparition) qui sont évoqués par le biais de quatre poursuivants d'armes (ibid., p. 540). Signalons que la cérémonie comporte également une effigie de la reine défunte (ibid., p. 538-539).

(122) La présence des membres de l'Hôtel lors des funérailles, ainsi que l'interruption de leurs charges au moment de la mise en terre de leur maître sont attestées chez les ducs de Bourgogne et, plus généralement, chez les princes français, influencés par le cérémonial royal au cours duquel les officiers de l'Hôtel du roi se démettent de leurs fonctions en jetant leurs insignes dans la fosse (Murielle GAUDE-FERRAGU, D'or et de cendres. La mort et les funérailles des princes dans le royaume de France au bas Moyen Âge, Villeneuve d'Ascq, P.U. du Septentrion, 2005, p. 146-152 ; Ralph GIESEY, Le roi ne meurt jamais. Les obsèques royales dans la France de la Renaissance, trad. Dominique EBNÖTHER, Paris, Flammarion, 1987, p. 115-126).

(123) Pour l'Espagne, ce sont bien sûr les blasons et cottes d'armes représentant les différents royaumes. Pour la Bourgogne, outre la présence de blasons, on signalera l'épée ducale utilisée depuis les funérailles de Philippe le Bon pour signifier le passage de la 
Après la mort du roi Ferdinand (23 janvier 1516) des honneurs funèbres lui sont aussi rendus à Bruxelles en l'église Saint-Michel-et-Gudule, les 14 et 15 mars ${ }^{(124)}$. À nouveau, le mélange des symboles est perceptible. Des blasons représentant les différents royaumes du défunt sont présents dans le cortège et dans la collégiale. Ceux-ci sont accompagnés à plusieurs reprises de colliers de la Toison d'or (sur un grand drap tendu dans la nef, ainsi que sur des draps d'or cramoisi accrochés à la chapelle ardente, et six grands blasons à côté du cercueil) ${ }^{(125)}$. Toute une symbolique royale est déployée et associée à la personne de Charles de Habsbourg. Une couronne est placée sur la représentation du corps du défunt ${ }^{(126)}$, tandis que le sermon prononcé le deuxième jour par Michel de Pavie $(† 1517)$, doyen de Notre-Dame de Cambrai, insiste sur la transmission des titres et des valeurs entre Ferdinand et Charles ${ }^{(127)}$. Enfin, une cérémonie de transmission de pouvoir, similaire à celle de 1504, a lieu. Le héraut Toison d'or y proclame donne Jehanne et don Charles, par la grace de Dieu, roy catholiques, heritiers de tous ses royaulmes et principaultez ${ }^{(128)}$.

Les liens tissés entre les princes austro-bourguignons et les Rois catholiques lors des funérailles bruxelloises renforcent le caractère royal des premiers grâce à la symbolique monarchique qui y est déployée, mélange d'éléments bourguignons et espagnols. Les deux cérémonies bruxelloises insistent sur la transmission directe de la Couronne, une idée bien ancrée dans

souveraineté entre le mort et le vif. Voir JEAN MOLINET, Chroniques, op. cit., p. 541 ; et plus généralement M. GAUdE-FerRAGU, D'or et de cendres, op. cit., p. 229-236.

(124) Sur le contexte qui entoure la cérémonie bruxelloise de 1516, voir P. CHAUNU \& M. ESCAMILla, Charles Quint, op. cit., p. 97-105. À propos des cérémonies funèbres en l'honneur des Rois catholiques, en Espagne et en dehors, voir Rafael DomínGUEZ CASAS, « Exequias borgñonas en tiempos de Juana I de Castilla », dans Miguel Ángel ZaLAma, ed., Juana I. Arte, poder y cultura en torno a una reina que no gobernó, Valladolid, Centro de Estudios de Europa Hispánica, 2010, p. 259-286 ; Friedrich EdELMAYER, « Die Leichenfeiern für Ferdinand den katholischen in den Niederlanden (1516) », dans Lothar Kolmer, ed., Der Tod des Mächtigen. Kult und Kultur des Todes spätmittelalterlicher Herscher, Paderborn, Ferdinand Schöningh, 1997, p. 229-261 ; Elisa RUIZ GARCíA, « Aspectos representativos en el ceremonial de unas exequias reales (a. 1504-1516) », dans En la España Medieval, t. 26, 2003, p. 263-294. Remarquons également que ces deux cérémonies bruxelloises s'intègrent, dans le temps long, à un processus plus général de transferts culturels entre les traditions funéraires des Maisons de Bourgogne-Habsbourg et Castille-Aragon, qui se poursuit tout au long du $\mathrm{XVI}^{\mathrm{e}}$ siècle jusqu'à créer un modèle original propre aux souverains des Pays-Bas du Nord et du Sud, et que la noblesse copiera également (Hans CoOLS, "Uitvaarten als intredes. De scenografie bij aristocratische begrafenissen in de Bourgondisch-Habsburgse landen en in de jonge Republiek », dans Mario DAmEN \& Louis Sicking, eds, Bourgondië voorbij. De Nederlanden 1250-1650. Liber alumnorum Wim Blockmans, Hilversum, Verloren, 2010, p. 193-207).

(125) RÉMI DupuYs, Les exeques, op. cit., f. 139r et 142v-143v.

(126) Ibid., fol. 169r.

(127) Le sermon est intitulé Homo quidam nobilis abiit in regionem longinquam accipere sibi regnum (ibid., f. 179v-195r). Sur le personnage, voir James K. FARGE, Art. " Michel Pavie », dans P.G. Bietenholz \& Th.B. Deutscher, eds, Contemporaries of Erasmus, op. cit., t. 3, 1987, p. 62-63.

(128) RÉMI DupuYs, Les exeques, op. cit., fol. 196r-v. Dans ce cas également, l'épée symbolise la passation de pouvoir entre Ferdinand et Philippe (ibid., fol. 197v). 
les mœurs politiques françaises ${ }^{(129)}$. Toutefois, dans le cas présent, une telle démonstration occulte partiellement le fait que Philippe et Charles sont, d'une part, rois-consorts de Castille avec la reine Jeanne, d'autre part, sont astreints à prêter serment devant les Cortès espagnols avant d'être reconnus comme souverains légitimes.

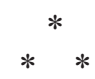

L'élaboration de liens entre les princes austro-bourguignons et les Rois catholiques, volontairement décomposée par nous en trois temps (rencontres princières, biographies royales et hommages posthumes), fonde leur image royale. Elle permet de renforcer leur légitimité à régner sur des territoires ibériques qui leur sont encore partiellement hostiles. Car, ne l'oublions pas, les voyages de Philippe et de Charles dans la péninsule ambitionnent avant tout de leur gagner le soutien des élites politiques espagnoles, et cela nos auteurs l'ont parfaitement compris.

\section{Les forces vives des royaumes ibériques}

La quête de légitimité qui amène Philippe et Charles en Espagne les conduit à la rencontre de deux groupes politiques qui forment les forces vives des royaumes ibériques : la haute noblesse et les Cortès. Leurs rencontres constituent autant de points d'orgue dans nos textes, autant de moments que les auteurs s'emploient à instrumentaliser.

\section{Noblesses ibériques}

La relation entre le prince et sa noblesse est régulièrement mise en scène dans nos textes. L'importance conférée à la haute noblesse en particulier repose sur plusieurs facteurs. N'oublions pas tout d'abord que Philippe et Charles sont en permanence entourés, tant aux Pays-Bas qu'en Espagne, par des membres de la haute noblesse qui composent, pour une bonne part, le groupe restreint des conseillers et adjuvants du pouvoir ${ }^{(130)}$. En Espagne, plus spécifiquement,

(129) Voir le chap. 10, Le roi ne meurt jamais, de R. GIESEY, Le roi ne meurt jamais, op. cit., p. 267-290.

(130) Ainsi, dans le cadre " bourguignon " stricto sensu, ANTOINE DE LALAING, Voyage, op. cit., p. 126, décrit régulièrement l'entourage noble du prince, comme le 4 novembre 1501, à Bruxelles. Sur l'entourage nobiliaire de Philippe et de Charles, voir Jean-Marie CAUCHIES, "Croit conseil" et ses "ministres". L'entourage politique de Philippe le Beau (1494-1506) », dans Alain MARCHANDISSE \& Jean-Louis KuPPER, eds, $\dot{A}$ l'ombre du pouvoir. Les entourages princiers au Moyen Âge, Genève, Droz, 2003, p. 385405 ; ID., « No tyenen más voluntad de yr a España que de yr al infierno ! Los consejeros "flamencos' de Felipe el Hermoso y del joven Carlos V frente a la herencia española ", dans Antonio Álvarez-OSSORIO Alvariño \& Bernardo J. García García, eds, La Monarquía de las naciones. Patria, nación y naturaleza en la Monarquía de España, Madrid, Fundación Carlos de Amberes, 2004, p. 121-130 ; H. CoOLs, Mannen met macht, op. cit., avant tout, chap. 2 : Aristocratische instellingen in de Bourgondisch-Habsburgse landen, ca. 1475-1530, p. 29-46. 
le poids économique et social de la noblesse lui confère une place tout à fait exceptionnelle sur l'échiquier politique, et ce même après les réformes des Rois catholiques ${ }^{(131)}$. Il importe aussi de souligner qu'une part importante de la noblesse castillane redoutait que Ferdinand d'Aragon s'impose dans leur pays. Cette faction était donc toute disposée à accueillir Philippe en Castille ${ }^{(132)}$. Pour toutes ces raisons, il est donc tout à fait compréhensible que la noblesse occupe une place de choix dans des textes visant à légitimer le prince.

Chez Antoine de Lalaing, cette mise en scène de la noblesse transparaît dès l'arrivée de Philippe en Navarre. À Fontarabie, il est accueilli, devant les portes de la cité, par le commandeur majeur de l'Ordre de Santiago, Don Francisco de Zúñiga Avellaneda y Velasco († 1536), comte de Miranda(133), ainsi que de moult notables gens habillés à la fachon d'Espaigne ${ }^{(134)}$. Notons qu'outre la haute noblesse navarraise, Lalaing met ici en lumière l'un des trois grands ordres espagnols, celui de Santiago, sorte de pendant ibérique de la Toison d'or bourguignonne. Il décrit ensuite les spécificités de chacun des grands ordres espagnols ${ }^{(135)}$. Les autres entrées s'enchaînent sur le même mode, l'auteur prenant toujours grand soin d'illustrer les membres les plus éminents de la noblesse, que ce soit à Burgos (12 février 1502), à Valladolid (28 février $1502)$, à Tolède (7 mai 1502) ou à Barcelone $(18 \text { janvier } 1503)^{(136)}$. On trouve même dans son texte des listes des grands nobles des différents royaumes ${ }^{(137)}$.

(131) Miguel Ángel LAdero QuesadA, « La genèse de l'État dans les royaumes hispaniques médiévaux (1250-1450) », dans Christian HERMANN, ed., Le premier âge de l'État en Espagne, 1450-1700, Paris, CNRS Éditions, 1989, p. 9-65 (ici p. 50-55).

(132) Voir J.-M. CAuchies, Philippe le Beau, op. cit., p. 139-140 et 192-195.

(133) Sur ce noble espagnol, vice-roi de Navarre après la conquête de 1512, voir Santiago Fernández ConTi \& Félix LABRAdOR ARroyo, « Zúñiga Avellaneda y Velasco, Francisco de », dans DBE, t. 50, 2013, p. 996-999; Thomas B. DEUTSCHER, « Francisco de Zúñiga », dans D.G. Bietenholz \& Th.B. Deutscher, eds, Contemporaries of Erasmus, op. cit., t. 3, p. 479-480.

(134) Antoine de Lalaing, Voyage, op. cit., p. 148.

(135) Ibid., p. 191-192. La présentation des ordres hispaniques par Lalaing se veut très descriptive et y lire une hiérarchisation entre eux et l'ordre de la Toison d'or nous semble compliqué, faute d'éléments plus clairs dans le récit, et également parce que les uns et l'autre sont très différents. Les ordres espagnols ont plus clairement que la Toison d'Or une vocation militaire liée à l'histoire de la Reconquista, ainsi qu'une relative indépendance par rapport au pouvoir royal, indépendance qui s'amenuise toutefois sous les Rois catholiques (Philippe JosserAnd, Église et pouvoir dans la Péninsule ibérique. Les ordres militaires dans le royaume de Castille (1252-1369), Madrid, Casa de Velàzquez, 2004, p. 233-297 ; J. PÉREZ, Isabelle et Ferdinand, op. cit., p. 184-187). Sur le plan intellectuel, on sait que des liens existent entre la Toison d'or et les ordres de chevalerie ibériques, notamment dans le Llibre del Ordre de Cavayleria de Raymond Lulle (ca 1232-1315), dont la réception est bien attestée dans les milieux de cour français et bourguignons (A.J. VANDERJAGT, Qui sa vertu anoblist, op. cit., p. 68-69 ; Klaus OschemA, " Noblesse et chevalerie comme idéologie princière ? ", dans A.J. DACRE BOUlTON \& J.R. VEEnSTRA, eds, The Ideology of Burgundy, op. cit., p. 229-251 [ici p. 229-230]).

(136) Antoine De Lalaing, Voyage, op. cit., p. 152 (Burgos), 166 (Valladolid), 174-175 (Tolède) et 256 (Barcelone). Voir aussi Jean Molinet, Chroniques, op. cit., t. 2, p. 506 (Burgos), 507 (Valladolid), 514-515 (Tolède) et 517 (Barcelone).

(137) Antoine De Lalaing, Voyage, op. cit., p. 214 (Valence), 231-237 (Castille), 250 (Aragon), 260-261 (Catalogne). Philippe le Beau fait grand cas de ces rencontres. À Tolède, en 1502, il parle de plusieurs grandz ducz, marquis, princes et autres grands barons et seigneurs, de ceulx de son conseil, de l'estat de l'Esglise et d'autres ses officiers, 
Des éléments similaires sont présents chez d'autres auteurs : dans le Deuxième voyage, par exemple, à l'arrivée de Philippe à La Corogne (27 avril 1506) et à Monterrey (juin 1506) ${ }^{(138)}$, ainsi que chez Laurent Vital lors de l'entrée de Charles de Habsbourg à Becerril de Campos (31 octobre 1517) et à Valladolid (18 novembre). En cette dernière occasion, le chroniqueur consacre, non pas une liste comme Lalaing, mais un chapitre entier aux Grands d'Espagne venus accueillir leur maître ${ }^{(139)}$.

Cette mise en scène de la noblesse et de son souverain permet de signifier à la fois la grandeur du prince et sa légitimité puisque, en ces occasions, la fine fleur des Espagnes, en ce compris les membres éminents des grands ordres militaires, lui rend hommage. Parfois, ces événements donnent même lieu à une véritable soumission de la noblesse. C'est le cas à Llane (fin septembre 1517), lorsque, devant Charles de Habsbourg, les seigneurs de la ville luy vindrent faire la révérence en sa chambre [...] en luy présentant cours, corps et biens du tout à son command ${ }^{(140)}$. Il en va de même à Valladolid lors de son couronnement ${ }^{(141)}$.

La noblesse espagnole est considérée comme un groupe social sur lequel il faut compter pour régner car en elle réside la force du pays. C'est l'opinion d'Antoine de Lalaing. Alors qu'il présente les qualités de la cité de Valence, le chroniqueur souligne que de celle ville puèvent sortir, pour le besoing d'ung roy d'Arragon, mille homes d'armes à chevauls bardés; et fault entendre que tous les nobles du royame se tirent en la ville ${ }^{(142)}$. Diego de Guevara conseille également Philippe dans ce sens. Il doit exiger des Grands de comparaître devant lui et son épouse : Sire, ne vous abusés point, à ce que je puis entendre, que nul des grans maistres quy sont ycy ne voyse devers vous, se vous et la Royne ensamble ne les mandés ${ }^{(143)}$. L'anonyme du Deuxième voyage révèle que Philippe le Beau a très bien retenu la leçon. En effet, en 1506, alors que les tensions grandissent entre lui et Ferdinand d'Aragon, Philippe envoie Philibert,

gens de loy et notables dudict Toulette (PHILIPPE LE BEAU, Lettre à Englebert de Nassau, Tolède, 11 mai 1502, dans L.-Pr. GACHARD, ed., Collections de voyages, op. cit., t. 1, $\mathrm{n}^{\mathrm{o}}$ 4, p. 379).

(138) Deuxième voyage, op. cit., p. $432-434$ (La Corogne) et 438 (Monterrey). Il faut toutefois reconnaître que les listes données par Lalaing et l'anonyme - et a fortiori par Molinet qui les utilise - sont loin d'être exhaustives (ibid., p. 434, n. 5). Monterrey : Espagne, com. aut. Galice, prov. Orense, comarque Verín.

(139) Laurent Vital, Premier voyage, op. cit., p. 129-130 (Becerril de Campos) et 149-157 (Valladolid). Pour le chapitre sur les nobles (Comment plusieurs princes de Castille vindrent à Vailledoly veoir le Roy, pour luy faire la révérence), on verra ibid., p. 156-157. Vital offre une liste similaire lors de la cérémonie de réception de Charles comme roi de Castille, à Valladolid le 7 février 1518 (ibid., p. 223-224). Becerril de Campos : Espagne, com. aut. Castille-et-León, prov. Palencia, comarque de Tierra de Campos.

(140) Laurent Vital, Premier voyage, op. cit., p. 102.

(141) Ibid., p. 226. À cette occasion, l'auteur établit la liste des Grands qui ont prêté serment au roi (ibid., p. 226-229). On trouve également un récit plus court, mais avec le même sens, dans NiCAISE LADAM, Histoire, op. cit., fol. 114r. D'autres cas de soumission de la noblesse au prince sont présents dans ANTOINE DE LALAING, Voyage, op. cit., p. 148149, 151-152, 184, 190, 241 et 256 ; Deuxième voyage, op. cit., p. 433-434 et 436.

(142) Antoine De Lalaing, Voyage, op. cit., p. 211.

(143) Don Diego De Guevara, Lettre à Philippe le Beau, Villafranca, $1^{\text {er }}$ et 2 juin 1506, p. 516. 
seigneur de Veyré, dit La Mouche (ca 1450-1512)(144), gagner les princes dudict royaulme ou parti et du costé du roy don Philippe ${ }^{(145)}$. La noblesse doit donc, de gré ou de force, se rallier au prince ${ }^{(146)}$.

Outre les hommages, différentes stratégies existent pour y parvenir, notamment la séduction. Philippe et Charles tentent de charmer la noblesse ibérique en organisant et, parfois, en participant, à des festivités et des jeux nobiliaires, que ceux-ci soient typiquement espagnols (courses de taureaux et jeux de cannes) ou communs à la noblesse européenne (tournois et pas d'armes) ${ }^{(147)}$. En ces occasions, le prince s'habille à l'espagnole pour s'intégrer. À Tolède, le 25 juillet 1502, Philippe le Beau, habillé à la mode castillane, puis à la morisque, joua aux cannes, et courut à la jennette ${ }^{(148)}$. Lors d'un pas d'armes organisé en son honneur, à Valladolid, le 12 février 1518, Charles de Habsbourg porte une cappe à l'espaingnolle ${ }^{(149)}$. Cette volonté d'intégration s'étend également aux nobles bourguignons et espagnols qui se partagent, lors des tournois, blasons et symboles ${ }^{(150)}$. La littérature bourguignonne sert parfois même de trame à ces festivités, comme à Valladolid,

(144) Sur ce personnage, chevalier de la Toison d'or, premier écuyer, chambellan et conseiller de Philippe le Beau, ainsi que l'un de ses principaux agents en Espagne, on verra J.-M. CAUCHIES, Philippe le Beau, op. cit., p. 65-66 ; ID., "Veyré, Philibert », dans $D B E$, t. 49, 2013, p. 800-801 ; H. CoOLs, Mannen met macht, op. cit., p. 298-299.

(145) Deuxième voyage, op. cit., p. 411.

(146) Il en va d'ailleurs de même pour les princes de l'Église : [les] grans, prélatz et autres qui sont là [...] [doivent venir] pour démonstrer ladite bonne voulenté qu'ilz doivent avoir envers nous, comme à leurs naturelz seigneurs Roy et Royne (PHILIPPE LE BEAU, Lettre à don Diego de Guevara, s.l., s.d. (4 juin 1506), dans L.-Pr. GACHARD, ed., Collection des voyages, op. cit., t. $\left.1, \mathrm{n}^{\mathrm{o}} 16, \mathrm{p} .518\right)$.

(147) Les jeux et festivités sont nombreux (Philippe : AnTOINE DE LALAIng, Voyage, op. cit., p. 149, 153, 164-165, 166, 169, 171-172, 184-186, 188, 190, 192-195, 207, 218219, 230, 258, 260, 263 et 264 ; JeAn Molinet, Chroniques, op. cit., p. 506 ; Charles : Laurent Vital, Premier voyage, op. cit., p. 93, 101-103, 115, 126, 248-251 et 255). Parmi ces événements, deux sont tout à fait remarquables : un tournoi à Tolède, le 13 juin 1502 (ANTOINE DE LALAING, Voyage, op. cit., p. 184), et deux emprinses à Valladolid, en novembre-décembre 1517 et janvier-février 1518 (LAURENT VITAL, Premier voyage, op. cit., p. 165-177 et 184-223 ; NICAISE LADAM, Histoire, op. cit., f. 116r et 123r-127r). Des témoignages picturaux existent sous la forme de deux tableaux du château de La Follie à Ecaussinnes-d'Enghien, l'un présentant une course de taureaux, l'autre un jeu de cannes (voir CAUCHIES, Philippe le Beau, op. cit., p. 186-187).

(148) ANTOINE DE LALAING, Voyage, op. cit., p. 194-195. Il en va de même à Valladolid le 15 mars 1502, le 2 août (Ibid., p. 169). Parfois, le prince s'habille à la mauresque (ibid., p. 185,194$)$.

(149) Laurent Vital, Premier voyage, op. cit., p. 200. Il en va de même lors du premier pas d'armes de Valladolid (ibid., p. 170).

(150) Ibid., p. 167-169, 191, 213 (princes et nobles), 204, 212 (musiciens) et 214 (croix de saint André). Des cas similaires apparaissent chez ANTOINE DE LALAING, Voyage, op. cit., p. 188 (ici, des Castillans portent des croix de saint André et des fusils de Bourgogne), 230 et 250 . Il existe d'ailleurs des rapports évidents entre les jeux nobiliaires bourguignons et castillans, ce qui doit favoriser les rapprochements (Torsten HiLTMANN, «Un État de noblesse et de chevalerie sans pareilles ? Tournois et hérauts d'armes à la cour des ducs de Bourgogne ", dans W. PARAVicini, T. Hiltmann \& Fr. ViltarT, eds, La cour de Bourgogne, op. cit., p. 253-288 [ici p. 264-265]). 
où l'on s'inspire du roman du roy Percheforest ${ }^{(151)}$ pour mettre en scène le pas d'armes.

Dans nos textes, le rapprochement entre le prince et la noblesse ibérique - auxquels sont parfois joints les nobles bourguignons - s'opère grâce aux cérémonies d'hommage et au partage d'éléments issus de la culture nobiliaire, ce qui accroît la légitimité du prince en Espagne, légitimité qui se renforce encore lorsque celui-ci prête serment devant les Cortès.

\section{Les Cortès de Castille et d'Aragon}

Héritiers d'une conception de l'ordre social enracinée dans le Moyen Âge, les Cortès de Castille et d'Aragon assument un rôle politique fondamental en Espagne. C'est entre autres devant eux que le souverain doit prêter serment pour être considéré comme pleinement légitime. À la fin du Moyen Âge, cette cérémonie demeure celle qui, par excellence, fonde le pouvoir royal, car le sacre, tel qu'on le connaît par exemple en France, a disparu dans les royaumes espagnols. Il s'agit d'un contrat-serment ${ }^{(152)}$ : le roi jure de respecter les privilèges de ses pays et en échange ceux-ci, par le biais des représentants des trois États (clergé, noblesse, villes), jurent de lui obéir. C'est également devant les Cortès que, comme dans les Pays-Bas, les demandes d'aides extraordinaires doivent être introduites ${ }^{(153)}$. Philippe le Beau et Charles de Habsbourg ayant pour but premier d'entrer légitimement en possession de leurs royaumes

(151) Laurent Vital, Premier voyage, op. cit., p. 184. Le texte original, composé vers 1340 , à la cour de Hainaut, par un auteur anonyme, fut considérablement remanié au $\mathrm{XV}^{\mathrm{e}}$ siècle dans l'entourage de Philippe le Bon, notamment par David Aubert (Perceforest. Première Partie, ed. Gilles Roussineau, t. 1, Genève, Droz, 2007, p. IX ; voir aussi Christine FERLAMPIN-ACHER, Perceforest et Zéphir : propositions autour d'un récit arthurien bourguignon, Genève, Droz, 2010). Plus généralement, lors du premier voyage de Charles de Habsbourg en Espagne, le mélange entre symboliques bourguignonne et espagnole se manifeste constamment, comme à Valladolid (LAURENT VITAL, Premier voyage, op. cit., p. 152-153 et 212). Toutefois, Vital rappelle les limites de ce mélange hispano-bourguignon puisque vers la fin des festivités, les Espagnols refusent de participer à une emprinse où n'y avoit point ou peu de proffit (ibid., p. 222). B. ARAM, « Voyages from Burgundy to Castille », op. cit., p. 98-105, voit davantage une sorte de compétition culturelle entre Bourguignons et Espagnols dans les divertissements nobiliaires organisés lors des voyages de Philippe le Beau.

(152) Sur cette pratique, en général, dans l'Europe médiévale, voir François ForONDA, ed., Avant le contrat social. Le contrat politique dans l'Occident médiéval (XIII ${ }^{\text {- }}$ $X V^{e}$ siècle), Paris, Publications de la Sorbonne, 2011 ; Thierry Dutour, Sous l'Empire du Bien. "Bonnes gens » et pacte social (XIII $-X V^{e}$ siècle), Paris, Classiques Garnier, 2015, p. 363-380 et 394-396.

(153) M.A. LADERO QueSADA, « La genèse de l'État », op. cit., p. 25 (sur les Cortès plus généralement, voir p. 60-64) ; T.F. RUIZ, «Une royauté sans sacre », op. cit., p. 440441. Le serment devant les Trois États a également cours dans les Pays-Bas, notamment lors des Joyeuses entrées du prince. Les Bourguignons devaient donc être particulièrement sensibles à ce rôle joué par les Cortès (Jean-Marie CAUCHIES, « La signification politique des entrées princières dans les Pays-Bas : Maximilien d'Autriche et Philippe le Beau ", dans ID., ed., Fêtes et cérémonies aux XIV ${ }^{e}-X V I^{e}$ siècles. Rencontres de Lausanne (23 au 26 septembre 1993), PCEÉB, t. 34, 1994, p. 19-35 [ici p. 29-31] ; Marc BOONE, « L'État bourguignon, un État inventeur ou les limites de l'invention », dans W. PARAVICINI, T. HiLTMANN \& Fr. VILTART, eds, La cour de Bourgogne, op. cit., p. 133-156 [ici p. 141 s.]). 
ibériques, leurs prestations de serment devant les Cortès occupent une place centrale dans nos textes ${ }^{(154)}$.

Plusieurs rencontres avec les Cortès attendent donc Philippe - Tolède, le 22 mai 1502, Saragosse, le 27 octobre 1502, Valladolid, le 12 juillet 1506 - et Charles - Valladolid, le 7 février 1518. Ces événements sont autant d'occasions de présenter les princes austro-bourguignons comme les successeurs légitimes des Rois catholiques, ceux qui ont l'autorité sur les Cortès, et donc sur les sociétés espagnoles ${ }^{(155)}$. Enfin, lors de ces cérémonies, les princes austrobourguignons prêtent, on l'a dit, serment de respecter les lois du pays et les privilèges de chaque ordre ${ }^{(156)}$. Ils passent une sorte de contrat politique avec leur pays : en échange de la soumission des États, le souverain jure de respecter leurs droits et coutumes. Le serment de Charles, à Valladolid, est à ce titre des plus exemplaires :

Après viendrent les prélatz faire le meisme serment, en luy baisant la main. Après viendrent messeigneurs les princes et grantz maistres faire le meisme serment, comme le connestable, l'admirante, ducs, contes, marquis et barons, sans entre eulx avoir regard qui iroit le premier. Après iceulx viendrent aussi les procuradores des villes [...] et là viendrent tous les grants et aultres seigneurs ci-dessus nommez, aussi les procuradores des villes et des cytés, tous les ungz après les autres, faire le serment et hommaige ès mains dudict seigneur don Fernande. Ce faict, le Roy se leva de sa chayère et mist la main sur les sainctes évangilles et sur la croix, en faisant le serment, tel que les roys ses prédécesseurs ont acoustumet de faire; et ce faict, on commencha à chanter Te Deum laudamus ${ }^{(157)}$.

Autant dans le cas de Philippe que dans celui de Charles, leur présentation devant les Cortès constitue, aux yeux de leurs sujets espagnols, le fondement

(154) Rappelons-nous toutefois qu'au cours du règne des Rois catholiques, les Cortès sont très peu sollicités et demeurent sous le contrôle strict du pouvoir royal. Ils ne récupèrent une véritable influence qu'en période de vide du pouvoir, comme après les décès d'Isabelle et de Ferdinand (María ASENJO GONZÁLEZ, « La aristocracización política en Castilla y el proceso de participación urbana (1252-1520) », dans José Manuel NiETO SORIA, ed., La monarquía como conflicto en la Corona castellano-leonesa (ca 1230-1504), Madrid, Silex, 2006, p. 133-196 [ici p. 186-188] ; J. PÉREZ, Isabelle et Ferdinand, op. cit., p. 161-164).

(155) Tolède : Antoine DE Lalaing, Voyage, op. cit., p. 178-181 ; JEAn Molinet, Chroniques, op. cit., p. 517 ; PHILIPPE LE BEAU, Lettre à Englebert de Nassau, Tolède, 26 mai 1502, dans L.-Pr. GACHARD, ed., Collection des voyages, op. cit., t. $1, \mathrm{n}^{\mathrm{O}} 5$, p. 380 ; Saragosse : Antoine De Lalaing, Voyage, op. cit., p. 240-242 ; JeAn Molinet, Chroniques, op. cit., p. 517 ; Valladolid, 1506 : l'auteur du Deuxième voyage ne rend pas compte de la cérémonie ; Valladolid, 1518 : LaURent Vital, Premier voyage, op. cit., p. 223-226. Sur ces cérémonies, voir surtout J.-M. CAUChIES, Philippe le Beau, op. cit., p. 138-141 et 198 ; P. Chaunu \& M. Escamilla, Charles Quint, op. cit., p. 113-115 ; K. BRANDI, Charles Quint, op. cit., p. 83-84.

(156) Antoine de Lalaing n'hésite pas à rendre compte, dans son récit, des privilèges espagnols (ANTOINE DE LALAING, Voyage, op. cit., p. 165 [politique navale], 209-210 [droits de douanes], 237 [privilèges des rois et reines de Castille] et 249-250 [comparaison entre les coutumes d'Aragon et de Castille]).

(157) Laurent Vital, Premier voyage, op. cit., p. 225-226. Le serment de Philippe et de Jeanne à Tolède en 1502 est également tout à fait représentatif (ANTOINE DE LALAING, Voyage, op. cit., p. 179 ; JEAN MOLINET, Chroniques, op. cit., p. 517). 
de leur légitimité royale ${ }^{(158)}$, alors que les cérémonies bruxelloises, dont nous avons vu toute la portée légitimante aux yeux des Bourguignons, n'ont aucune valeur pour les Espagnols. Ce qui compte avant tout, aux yeux des Cortès et par extension des Espagnols, c'est l'idée de «naturalité » du prince, une façon de concevoir la succession légitime également en vigueur dans les Pays-Bas et que consacrent justement les Cortès ${ }^{(159)}$. Dans les royaumes ibériques, on considère que le prince doit être issu, par ses parents, de la terre sur laquelle il est appelé à régner, et, dans l'idéal, qu'il doit être éduqué selon les mœurs du pays. L'idée est particulièrement illustrée lors de la réception de Philippe, à Saragosse, en 1502, devant les Cortès d'Aragon :

Oultre plus, ledit roy de Castille, d'Arragon et de Cecile se tira en Arragon, où il fit assambler les Estas desdis royames, et, en presence de monseigneur et de madame, leur fit faire le serment que, aprèz son dechèz, ilz tenroyent à roy mondit seigneur l'archiduc, à cause de sa compaigne l'archiducesse, sa fille. Mais, se par après ledit roy avoit hoir masle et legitisme, ledit hoir possesseroit desdis royames venans de par lui et de toutes leurs appendences $^{(160)}$.

Philippe sera éventuellement roi-consort d'Aragon grâce à son épouse, Jeanne de Castille, héritière légitime de Ferdinand, et donc celle qui transmet le lien dynastique et le droit de régner ${ }^{(161)}$. Mais, si un héritier mâle vient à naître, ce dernier sera le nouveau prince naturel et coiffera la couronne d'Aragon en tant que véritable prince naturel.

(158) Les deux princes et leur personnel perçoivent bien l'importance de ces cérémonies (J.-M. CAUChIES, Philippe le Beau, op. cit., p. 140-141 et 198-199; P. ChaunU \& M. EsCAMILla, Charles Quint, op. cit., p. 102 ; K. BRANDI, Charles Quint, op. cit., p. 83-84).

(159) En Espagne, le lien de naturalité « intègre son détenteur au corps politique du pays ». Il peut également s'entendre en tant que « vassalité naturelle », les vassaux naturels du roi, ceux qui lui doivent naturellement obéissance (M.A. LADERO QUESADA, « La genèse de l'État », art. cit., p. 19-20 et 26-27). Dans les Pays-Bas, les États généraux se présentent également comme les gardiens de la naturalité du prince. Ce concept s'exprime à la mort de ce dernier, à travers la reconnaissance de son successeur, notamment à la mort de Philippe le Beau (Robert WeLlens, «Les États généraux et la succession de Philippe le Beau dans les Pays-Bas », dans Liber memorialis Émile Cornez, LouvainParis, Nauwelaerts, 1972, p. 125-159 [ici p. 140]) ou encore lors des Joyeuses entrées (J.M. CAUCHIES, «La signification politique des entrées princières », op. cit., p. 23 ; Élodie LECUPPRE-DESJARDIN, La ville des cérémonies. Essai sur la communication politique dans les anciens Pays-Bas bourguignons, Turnhout, Brepols, 2004, p. 135-158). Enfin, dans la langue utilisée par nos auteurs (le moyen français), l'adjectif «naturel » désigne précisément une chose qui est le produit de la nature, non de l'homme, et dont le lien avec la terre est consubstantiel, donc le plus légitime qui soit («Naturel, -elle», dans Trésor de la Langue française, en ligne, http://atilf.atilf.fr/dendien/scripts/tlfiv5/visusel.exe?58;s=3 $242085555 ; \mathrm{b}=3 ; \mathrm{r}=1 ; \mathrm{nat}=; \mathrm{i}=3$ (dernière consultation, le 10 août 2016).

(160) Jean Molinet, Chroniques, op. cit., p. 517.

(161) En Castille, Philippe est également présenté comme roi-consort dans le testament d'Isabelle la Catholique (J. PÉREZ, Isabelle et Ferdinand, op. cit., p. 375 ; Luis VÁZQUEZ DE PARGA, ed., Testamento y codicilo de la Reina Isabel la Católica, 12 de octubre y 23 de noviembre de 1504, Madrid, Ministerio de Educacion y Ciencia, 1969). Soulignons qu'une différence fondamentale existe dans la transmission du pouvoir en Castille et Aragon : tandis qu'en Castille la femme héritière est détentrice en droit de la Couronne, en Aragon, elle peut seulement transmettre les droits à celle-ci. 
Il y a donc ici un véritable défi pour nos auteurs, celui de présenter leur maître comme un prince légitime, et donc partiellement « naturel », ce qui dans le cas de Philippe peut relever de la forgerie. En ce qui concerne Charles de Habsbourg, la démonstration ne semble en effet pas poser trop de problèmes, vu ses origines castillanes et aragonaises. Nicaise Ladam le présente comme le successeur légitime de Ferdinand d'Aragon, sans juger nécessaire d'argumenter longuement :

Dont pour lequel soubz ses titles et armes

Le sang d'Austrice a cause d'estre en larmes

Comme premier et certain successeur

Pour en Castille estre vray possesseur ${ }^{(162)}$.

Par contre, les auteurs ont bien conscience que présenter Philippe le Beau en tant que souverain naturel tient de l'hyperbole. Jean Molinet, par exemple, en revient parfois à la réalité en présentant Philippe comme roi par son épouse :

Nous avons roy fort comme Gedeon,

Castille en main et Grenade et Leon,

Sceptres royaulx de glorieuse fame ;

Tel se gaudit qui n'a de par sa femme

Sy haultain bruit ne sy clere fortune :

Entre cent mile on n'en treuve point une ${ }^{(163)}$.

Le personnel de Philippe semble lui aussi éprouver des réticences à le considérer comme prince " naturel » en Castille. Philibert Naturel, prévôt d'Utrecht et ambassadeur à Rome (ca 1450-1529), déconseille par exemple à son maître d'aller dîner à l'extérieur de son palais, comme en vostre païs naturel, car Philippe n'est pas accoutumé à la nourriture. Il n'est donc pas prince $\ll$ naturel $»(164)$.

(162) NiCAISE LADAM, Mémoire et Épitaphe, op. cit., p. 89, v. 23-26. C. Thiry, l'éditeur du Mémoire, considère que ces vers portent la marque de l'incertitude de la succession de Charles au trône aragonais (ibid., p. 122). Plus loin, Ladam évoque également Charles comme l'heritier apparant (ibid., p. 117, v. 809) de Ferdinand, expression qui signifie à la fois, selon Thiry, « distingué, illustre, de haut rang » et " plausible » dans le sens juridique du terme (ibid., p. 154). En effet, Charles devait également être roi-consort de Castille avec sa mère, mais il passe outre ces dispositions et se fait proclamer roi à Bruxelles le 14 mars 1516 (J. PÉREZ, Isabelle et Ferdinand, op. cit., p. 379-380).

(163) JEAN MOLINET, XLI Cours vertueux, op. cit., p. 390, v. 43-48. L'idée est aussi présente chez l'auteur du Deuxième voyage, p. 389, et chez les officiers de Philippe, comme Don Diego De Guevara, Lettre à Philippe le Beau, Villafranca, $1^{\text {er }}$ et 2 juin 1506, p. 516 ; (ID., Lettre à Philippe le Beau, s.l., s.d. [6 juin 1506], p. 519).

(164) Je sçay, tant par la costume du païs que aussi pour la conservation de vostre personne, vous n'estes plus si comun à aller disner dehors ou soupper comme en vostre païs naturel ; aussi n'est-il besoing. Et vous advertiz, Sire, pour vostre bien, qu'il n'y a prince au monde qui ait plus mestier de soy garder que vous : à quoy n'y a pas grant affaire, s'il vous plaist, car vous avez des gens du païs naturels, qui saront très-bien faire l'office. Il n'est nul besoing d'aller mengier dehors. Et pour ce que les viandes du roy domp Fernande ne sont guères à vostre complexion et adoubées à vostre appétit, je croy que n'irés guères mengier avec luy, et vous ferez bien, mesmement en temps d'estez que vous estes hors de vostre nativité ; et à ceste cause est nécessité que mengiez des viandes selon 
Par moment, toutefois, les auteurs ne s'embarrassent pas trop de ces « détails ». Lors de la cérémonie funèbre d'Isabelle de Castille, organisée à Bruxelles en la collégiale Saint-Michel-et-Gudule, le 14 janvier 1505, la transmission directe de la puissance souveraine d'Isabelle au couple archiducal est signifiée. Nous avons en effet vu qu'à l'issue de cette cérémonie Philippe est proclamé dom Philippe [...] par la grace de Dieu roy [...] de Castille, de Leon et de Grenate et qu'ensuite il adopte une titulature par laquelle il se présente comme Philippe, par la grace de Dieu (nous soulignons) roy de Castille, de Leon et de Grenate, archiduc d'Austrice, prince d'Arragon et de Cecille, etc ${ }^{(165)}$. Ni Jeanne, ni encore moins les Cortès n'apparaissent comme le lien entre le prince et la royauté. C'est à Dieu qu'il doit sa couronne ${ }^{(166)}$.

Les nombreuses réceptions des princes de Bourgogne-Habsbourg devant les Cortès permettent à nos auteurs d'affirmer l'image de souverains pleinement légitimes parce que reconnus comme tels par les représentants des différents corps sociaux. Ce « capital » en légitimité s'ajoute à celui acquis auprès de la noblesse et permet de présenter Charles et, chez certains, Philippe comme les princes naturels des Espagnes.

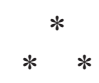

La description des rapports entre Philippe et Charles, et les forces vives de leurs royaumes ibériques achève d'installer ces princes comme des monarques légitimes d'Espagne. Ils ont reçu les serments d'allégeance des nobles et partagé leurs jeux. Ils se sont soumis, surtout, aux cérémonies de contratsserments devant les Cortès, s'assurant par là la fidélité des représentants

vostre complexion (PhILIBERT NATUREL, Lettre à Philippe le Beau sur les précautions $q u$ 'il doit prendre pour son manger, Rome, 7 juin 1506, dans L.-Pr. GACHARD, ed., Collection des voyages, op. cit., t. $1, \mathrm{n}^{\circ} 20$, p. 523-524). Remarquons que la « naturalité » à laquelle Naturel fait référence dépasse le cadre strictement politique pour embrasser la sphère culturelle (alimentation), voire même médicale (l'intolérance alimentaire de Philippe pour certains aliments auxquels il n'est pas habitué en tant qu'étranger au pays). Enfin, en tentant de dissuader son maître de dîner dehors, Naturel craint aussi qu'il soit empoisonné. Sur ce personnage, voir Daniel CoEnEN, « Naturel ou Naturelli, Philibert », dans Nouvelle Biographie nationale, t. 5, Bruxelles, Académie royale de Belgique, 1999, p. 273-276.

(165) JeAn Molinet, Chroniques, op. cit., p. 540-541.

(166) À la suite de la proclamation du 14 janvier 1505, Philippe fait réaliser un nouveau grand sceau pour les Pays-Bas où il apparaît, sans Jeanne, comme roi, par la grâce de Dieu, de Castille, de Léon et de Grenade (DEI + GRA + REGIS + CASTELLE + LEGIONIS + GRANATE), et portant le collier de la Toison d'or. Le sigillaire confirme les impressions données par les sources écrites (René LAURENT, « Le grand sceau de majesté des archiducs Maximilien d'Autriche et Philippe le Beau (1484-1496) », dans Jean-Marie Duvosquel, Jacques NAZET \& André VANRIE, eds, Les Pays-Bas bourguignons. Histoire et Institutions. Mélanges André Uyttebrouck, Bruxelles, Archives et Bibliothèques de Belgique, 1996, p. 287-295 ; ID., Les sceaux des princes territoriaux belges de 1492 à 1794, Bruxelles, Archives générales du Royaume, 1997, p. 14-15 ; M.J. ONGHENA, De iconografie van Philips de Schone, Bruxelles, Palais des Académies, 1959, $\mathrm{n}^{\text {os }}$ 187-188, p. 327-328). Soulignons toutefois que l'expression « par la grâce de Dieu » apparaît dans la titulature bourguignonne dès Philippe le Bon. La principale originalité ici est de la placer devant le titre de roi. 
des Trois ordres espagnols. Faisant leurs les conseils des chroniqueurs, et s'appuyant sur l'héritage des Rois catholiques, ils sont désormais, aux yeux de nos auteurs, pleinement investis de cette dignité royale nouvellement acquise.

\section{Conclusions}

Nous nous sommes efforcé, au fil de ces pages, de présenter toute la richesse de textes nés de la rencontre entre les Bourguignons et l'Espagne. Trois aspects ont marqué notre progression : les conseils donnés au prince afin de l'aider à gouverner ses royaumes, les liens dynastiques entre eux et les Rois catholiques, la description de leurs rapports avec la société politique espagnole (noblesse et Cortès). Par ces trois aspects, Antoine de Lalaing, Jean Molinet ou Laurent Vital entendent tracer les contours d'une royauté nouvelle, pleinement légitime, pour cette Maison de Bourgogne-Habsbourg qu'ils défendent et illustrent dans leurs écrits, et ceci au moment même où des voix s'élèvent contre la présence de leurs maîtres dans la péninsule ibérique ${ }^{(167)}$.

On pourrait donc dire que tous les textes examinés ici participent d'une stratégie, pas toujours pleinement consciente, d'intégration des royaumes ibériques à la mosaïque des possessions de la Maison de BourgogneHabsbourg. L'objectif est de donner une cohérence, sur le papier et donc dans les esprits, à un espace et à un pouvoir politiques qui apparaissent, en cette orée du $\mathrm{XVI}^{\mathrm{e}}$ siècle, bien plus morcelés et vulnérables que jamais. D'autres thématiques émergent en effet qui tendent à prouver que ce désir d'intégration est bien réel. Il y a tout d'abord une tendance à présenter le peuple - cette catégorie lâche et englobante de la pensée sociale médiévale -, dans les PaysBas et en Espagne, comme partageant des sentiments communs et identiques à l'égard de leur souverain ${ }^{(168)}$. L'idée est bien entendu de rapprocher symboliquement des populations qui n'ont que peu de choses en commun. Certains auteurs rêvent d'ailleurs que dans le futur des liens forts lieront les peuples sur lesquels règnent leurs maîtres, en particulier à travers un conseil royal où les différentes « nations » seraient représentées ${ }^{(169)}$. Sur le plan de

(167) Voir supra, p. 861-862 (début du point 4).

(168) C'est le cas par exemple à l'arrivée de Philippe en 1506 ou à sa mort à Burgos en septembre de la même année (JEAN Molinet, Les regrés de la mort, op. cit., p. 415, v. 145-148 ; ID., Chroniques, op. cit., p. 586 ; Deuxième voyage, p. 451-452 ; PHILIBERT, seigneur de Veyré, ChARLES DE POUPET, seigneur de La Chau(1)x, Lettre à Thomas de Plaine, chancelier de Bourgogne, et Guillaume de Croy, seigneur de Chièvres, Burgos, $1^{\mathrm{er}}$ mai 1506, dans L.-Pr. GACHARD, ed., Collection des voyages, op. cit., t. 1, no 9, p. 506).

(169) Jean Molinet parle d'un personnel politique qui sera composé d'Espaignars fors, Bourguignons ou Germains (JEAN MOLINET, Ballade touchant le voyaige d'Espaigne, op. cit., p. 382, v. 22). Cette espérance sera d'ailleurs partiellement concrétisée par Charles Quint à travers le remaniement de sa cour et de son conseil royal, dès le début des années 1520, même si ses sujets bourguignons et espagnols n'y sont pas tous favorables. Voir supra, p. 870, n. 130 ; René VERMEIR, « La construction de l'Empire. L'origine des transformations institutionnelles en Espagne au XVI siècle", dans Marc BoONE \& Marysa DEMOOR, eds, Charles $V$ in Context. The Making of a European Identity, Bruxelles-Gand, Ghent University Press-VUB University Press, 2003, p. 47-60 ; José Manuel CALDERÓN ORTEGA, «Felipe el Hermoso, Fernando el Católico y la instauración de la Casa de Austria en Castilla », dans Friedrich EDELMAYer \& Alfredo AlVAR EzQUERRA, eds, 
la géographie elle-même, on découvre des tentatives pour relier Espagnes et Pays-Bas au sein d'un ensemble politique cohérent. Les expressions "pays de par-deçà » et « pays de par-delà », caractéristiques de la culture politique bourguignonne ${ }^{(170)}$, apparaissent dans nos textes afin de situer de manière relative la péninsule ibérique et les Pays-Bas (« pays de par-delà » et/ou « pays de par-deçà $\gg)^{(171)}$. À travers des sémantiques très diverses se manifeste ainsi l'ambition d'une unité politique entre des territoires et des hommes très différents. L'élaboration d'une image royale pour les princes de la Maison de Bourgogne-Habsbourg en Espagne s'intègre donc pleinement à ce dessein plus vaste.

Les textes dont il a été question dans ces pages révèlent au final les premières tentatives des écrivains bourguignons d'inventer une royauté, un territoire et un système politique neufs pour leurs princes, au moment où une couronne royale apparait plus que jamais à portée de main pour le lion de

Fernando I, 1503-1564. Socialización, vida privada y actividad pública de un Emperador del Renacimiento, Madrid, Sociedad Estatal de Conmemoraciones Culturales, 2004, p. 133-166 ; José MARTínEZ MilláN, " La evolución de la corte castellana durante la segunda regencia de Fernando (1507-1516) »; Raymond FAGEL, « Un heredero entre tutores y regentes : casa y corte de Margarita de Austria y Carlos de Luxemburgo (15061516) »; Manuel Rivero Rodríguez, José Martínez Millán \& Carlos Javier DE CARLOS MORALES, «La conflictiva representación de los reinos en el servicio de Carlos V (1516-1522) »; Félix LABRADOR ARROYO, Manuel Rivero RODRÍGUEZ \& Carlos Javier DE CARlos Morales, « En busca del equilibrio en la corte de Carlos V (1522-1529) », dans J. MARTínez MiLlán, ed., La corte de Carlos V, t. 1/1, op. cit., p. 103-113, 115-140, $141-206$ et 207-259.

(170) On sait que, sous les ducs de Bourgogne, cette expression a permis de rendre compte, dès Philippe le Bon, du caractère bicéphale que prenaient, au fur et à mesure des acquisitions, les terres contrôlées par le duc. Les Pays-Bas, au Nord, et les deux Bourgognes, au Sud, furent appelés tantôt " pays de par-deçà ", tantôt " pays de pardelà », l'expression changeant en fonction de l'endroit où se trouve de celui qui l'emploie. Après la mort de Charles le Téméraire en 1477, l'amoindrissement de l'espace sud au profit de la France rendit moins nécessaire son usage, bien qu'il perdura jusqu'au $\mathrm{XVI}^{\mathrm{e}}$ siècle (Jean-Marie CAUCHIES, " "Des pays joinctz et uniz en concordeet obeissance"... et de la difficulté de les nommer : l'héritage ducal bourguignon sous la plume des indiciaires Jean Molinet et Jean Lemaire de Belges (fin $\mathrm{XV}^{\mathrm{e}}$-début XVI ${ }^{\mathrm{e}}$ siècle) ", dans Sylvie LAIGNEAUFontaine, ed., "Petite Patrie ». L'image de la région natale chez les écrivains de la Renaissance. Actes du colloque de Dijon, mars 2012, Genève, Droz, 2013, p. $67-77$ [ici p. 74-75]). L'expression se retrouve également à la même époque dans le lexique politique français (J. DUMONT, Lilia florent, op. cit., p. 340-341).

(171) Laurent Vital est celui qui permet de mieux saisir le sens de cette expression. La mer constitue une ligne de démarcation objective entre les deux espaces puisqu'il parle des pays de Charles tant de dechà que delà la mer (LAURent Vital, Premier voyage, op. cit., p. 8). Le terme reparaît dans sa chronique, notamment lors de la rencontre entre l'auteur et un artisan natif de Saint-Omer. La discussion entre les deux hommes donne toute sa mesure à la double expression, voire lui ajoute de la complexité car on comprend qu'elle peut également toujours être utilisée pour qualifier les Pays-Bas et les duché et comté de Bourgogne (ibid., p. 105). Des variantes de la double expression se retrouvent chez les autres auteurs. Les Pays-Bas y sont parfois désignés comme le pays dambas (NiCAISE Ladam, Histoire, op. cit., fol. 114r ; JeAn De VANDENESSE, Mémoires, op. cit., p. 57) ou païs d'embas (Deuxième voyage, op. cit., p. 421, 448 et 450-451). JEAN MOLINET, Chroniques, op. cit., p. 517, parle lui des jouvenceaulx de par dechà, jeunes-gens de la suite de Philippe indisposés par le climat péninsulaire (sur la perception du territoire bourguignon chez Molinet, on verra Ph. FRIEDEN, La Lettre et le miroir, op. cit., p. 39). 
Bourgogne, bien plus qu'elle ne l'était au temps de Philippe le Bon et Charles le Hardi/Téméraire, tout en préservant des traditions bourguignonnes, sur le plan symbolique notamment. Les œuvres d'un Lalaing, d'un Molinet, d'un Vital et de tant d'autres fixent un instantané de l'évolution de la pensée politique bourguignonne en ce début de $\mathrm{XVI}^{\mathrm{e}}$ siècle, quelques années avant que l'élection impériale de Charles de Habsbourg ne lui donne une tout autre dimension, teintée d'un universalisme que par moment l'on sent déjà poindre dans cette Espagne imaginée et rêvée.

\section{RÉSUMÉ}

Jonathan DuMont, Le lion enfin couronné. Pensée politique et imaginaire royal au cours des premiers voyages espagnols des princes de la Maison de BourgogneHabsbourg

Au début du XVI ${ }^{\mathrm{e}}$ siècle, les princes de la maison de Bourgogne-Habsbourg, Philippe le Beau et son fils Charles, effectuent plusieurs voyages à destination de l'Espagne, voyages qui vont radicalement transformer l'horizon de leurs possibles politiques. Philippe deviendra roi-consort de Castille avec son épouse Jeanne, Charles souverain de tous les royaumes espagnols en tant qu'héritier des Rois Catholiques. L'acquisition d'un titre, d'une dignité et de pouvoirs royaux constitue, depuis au moins la seconde partie du règne de Philippe le Bon, l'un des objectifs politiques majeurs des souverains des Pays-Bas. Cet article examine comment, alors que cette couronne apparaît comme plus tangible que jamais, les auteurs de cour gravitant autour de Philippe le Beau et Charles de Habsbourg élaborent des récits du voyage de leurs maîtres vers la Péninsule ibérique. Ils y dessinent une stature et une image royale permettant de légitimer Philippe et Charles dans leur nouvelle fonction. Ces auteurs font également émerger un modèle de monarchie particulier, qu'ils inscrivent à la croisée de l'action politique menée par les ducs de Bourgogne et les Rois catholiques, et qu'ils lient solidement à ce qu'ils considèrent comme les forces vives d'Espagne : les Grands et les Cortès. Ces auteurs témoignent enfin d'un moment d'intense réflexion politique dans les Pays-Bas, particulièrement centré sur la royauté, quelques temps seulement avant que l'élection impériale de Charles (désormais Quint) ne rebatte à nouveaux les cartes d'un imaginaire politique en mutation constante.

Pays-Bas bourguignons - Philippe le Beau - Charles Quint - Espagne - pensée politique

\section{SAMENVATTING}

Jonathan Dumont, De leeuw eindelijk gekroond. Politiek denken en koninklijke beeldvorming tijdens de eerste Spaanse reizen van de Habsburgs-Bourgondische vorsten

Aan het begin van de $16^{\mathrm{e}}$ eeuw brengen opeenvolgende reizen Filips de Schone en zijn zoon Karel naar het Spaanse schiereiland, een land waar hun politieke horizon drastisch wordt verlegd. Dankzij zijn huwelijk met Johanna wordt Filips er koning gemaal van Castilië; Karel, op zijn beurt, zal als erfgenaam van de Katholieke 
Koningen over alle Spaanse koninkrijken heersen. Ten minste sinds de tweede helft van de regeerperiode van Filips de Goede behoorden koninklijke titel, waardigheid en macht tot de belangrijkste politieke doelstellingen van de hertogen van Bourgondië. Dit artikel onderzoekt hoe schrijvers aan het hof van Filips en Karel de reizen van hun meesters naar het Spaanse schiereiland verhalen op het ogenblik dat de felbegeerde kroon eindelijk binnen bereik ligt. Om beide heersers' legitimiteit in hun nieuwe functie te benadrukken, schetsen de auteurs een nieuw beeld van het koningschap. $\mathrm{Zij}$ scheppen daarbij een eigen model voor de monarchie, gebaseerd op de politieke ondernemingen en ambities van zowel de hertogen van Bourgondië als de Katholieke Koningen. Een bijzondere nadruk ligt ook op de rol van de politieke krachten in Spanje: de Grandes en de Cortes. Het werk van deze schrijvers getuigt van de intense politieke beschouwingen omtrent koningschap die in de Nederlanden plaatsvonden vóór de keizerlijke verkiezing van Karel de kaarten van de politieke beeldvorming enkele jaren later eens te meer door elkaar schudde.

Bourgondische Nederlanden - Filips de Schone - Keizer Karel - Spanje - politieke ideeën en beeldvorming

\section{SUMMARY}

Jonathan Dumont, The Lion Finally Crowned. Political Thought and Royal Imaginary during the First Spanish Journeys of the Princes of the House BurgundyHabsburg

In the beginning of the $16^{\text {th }}$ century, the princes of the House of Burgundy-Habsburg, Philip the Fair and his son Charles, travelled several times to Spain. These travels radically transformed the scope of their political possibilities. Philip became king consort of Castile, along with his spouse Joanna, while Charles, as heir to the Catholic Kings, seized the crowns of all the Spanish Kingdoms. At least since the second half of Philip the Good's reign, the main political objective of the rulers of the Low Countries was the acquisition of a royal title, dignity, and power. This paper examines how, at a time when such a crown was in their reach, the courtly authors of Philip the Fair and Charles of Habsburg wrote elaborate travel accounts of their masters' journeys to Spain. In their narrations, they created a royal figure and image that legitimated their masters' place in their new function. They also established a new distinctive model of monarchy, which they inscribed at the crossroads of the political actions of the Dukes of Burgundy and those of the Catholic Kings. Furthermore, they connected this type of kingship to what they considered to be the main political forces of Spain: the Grandees and the Spanish Cortes. Lastly, their narratives capture a time of intense reflection on monarchical politics in the Low Countries shortly before the Imperial Election of Charles V redesigned the political landscape.

Burgundian Low Countries - Philip the Fair - Charles V - Spain - Political Thought 